\title{
ON THE BENEFITS OF A MONETARY UNION: DOES IT PAY TO BE BIGGER?*
}

\author{
Chiara Forlati ${ }^{\dagger}$ \\ This Draft: December 2014
}

\begin{abstract}
This paper revisits the question of the appropriate domain of a currency area using a New-Keynesian open economy model in which the world is split into two areas, each framed as a continuum of small open regions. We show that the adoption of a common currency like the euro can be beneficial for the members of the monetary union, since the spill-over effects generated by the inflationary policies of the small open economies are likely to outweigh the costs of not tailoring monetary policy to country-specific shocks. We also show that while the enlargement of the monetary union to another group of small open economies can bring about welfare gains for all countries involved, monetary integration of two large economies, such as the euro area and the U.S., will not. These findings can help to rationalize the process of the creation and enlargement of multi-country currency areas like the eurozone.
\end{abstract}

Keywords: New Keynesian Open Economy Macroeconomics, Optimal Monetary Policy, Currency Area, Terms-of-Trade Externality.

JEL Classification: E52, E61, F41.

\footnotetext{
*I would like to thank the editor Giancarlo Corsetti and two anonymous referees for suggestions that significantly improved the paper. For their helpful comments, I also thank Alessia Campolmi, Harald Fadinger, Jordi Galí, Stefano Gnocchi, Luisa Lambertini, Michael Reiter, Thijs Van Rens as well as all the participants of the seminars at Université de Lausanne, University of Vienna, Magyar Nemzeti Bank, Bilkent University, Ecole Polytechnique Fédérale de Lausanne, Kiel Institute for the World Economy and Universitat de las Islas Baleares.

†University of Southampton, Southampton UK, C.Forlati@soton.ac.uk.
} 


\section{Introduction}

What is the appropriate domain of a currency area? It might seem at first that the question is purely academic since it hardly appears within the realm of political feasibility that national currencies would ever be abandoned in favor of any other arrangement.(...) Certain parts of the world are undergoing processes of economic integration and disintegration, new experiments are being made and a conception of what constitutes an optimum currency area can clarify the meaning of these experiments. Mundell (1961)]

This paper revisits the issue of the appropriate domain of a currency area within a multi-country New-Keynesian open economy framework in which the objectives of the policy makers are fully micro-founded - i.e., derived directly from the welfare of the representative household 1 To our knowledge, we are the first to study within this class of models to what extent the process of formation and enlargement of a monetary union entails beneficial effects for its citizens by comparing the welfare gains of the adoption of a common currency or the extension of the currency area with the costs of renouncing country-specific stabilization policies. According to our main results, there can be welfare gains from sharing a common currency as long as the currency area is formed by a group of small open economies. Similarly, it can be desirable to enlarge the currency area to another group of small open economies. Conversely, integrating the monetary union with another big country cannot bring about sizeable welfare benefits. Our findings suggest that while the adoption and the enlargement of a common currency like the ones experienced in Europe could entail welfare benefits for all the countries involved, there is no reason to try to implement a monetary union between two big economic areas like the eurozone and the U.S.

In our model, the costs of losing monetary autonomy are those identified by Mundell (1961) as the main cost of being in a currency area: when countries share the same currency, monetary policy cannot properly stabilize country-specific shocks ${ }^{2}$ Conversely, the source of welfare benefits comes from the internalization of a standard terms-oftrade externality according to which open economy policy makers try to manipulate the terms of trade at other countries' expense. While this cannot be considered the only potential source of welfare benefits ensued from a monetary union - the literature on currency areas $3^{3}$ emphasizes, for example, the reduction in transaction costs $4^{4}$ the cut in hedging costs against exchange rate uncertainty, the increase in price transparency and the consequent increase in trade enhanced by all these factors 5 the anti-inflationary reputation effect: ${ }^{6}$ - this type of externality is the natural candidate to rationalize the

\footnotetext{
${ }^{1}$ See Rotemberg and Woodford (1997) and Benigno and Woodford (2005).

${ }^{2}$ Notice how by featuring nominal rigidities and labor immobility across countries, the New-Keynesian open economy frameworks are more suited than others to capturing the costs of a monetary union as originally described in Mundell (1961). This is one of the main reasons why we put our contribution within this literature.

${ }^{3}$ For a recent review of this literature, see Silva and Tenreyro (2010).

4 Alesina and Barro (2002) incorporate transaction costs - in the form of trade costs - into a model and show that the desirability of currency unions increases as the world number of countries rises and the average country size falls. Yet, in their analysis, the objectives of the policy makers are ad hoc.

${ }^{5}$ There is a vast empirical literature investigating the effects on trade between countries of adopting a common currency. See, for instance, Rose and van Wincoop (2001) and Silva and Tenreyro (2010).

${ }^{6}$ Note that the sources of gains deriving from the adoption of a monetary union are mostly microeconomic and thus difficult to embed into a standard open economy model, as a welfare analysis would require. Apart from the internalization of policy externalities here considered, the other main source of macroeconomic benefits identified by the literature is the possible improvement in the ability of the central bank to commit
} 
existence of a currency area within a New-Keynesian framework: a framework which is widely used for monetary policy analysis. Indeed, the terms-of-trade externality arises implicitly in many New-Keynesian open economy models and has been extensively studied in the open macro literature 7 which, however, tends to underestimate the ensued welfare losses, by usually considering a two country setup 8

Differently, we use a multi-country small open economy framework. This modeling choice allows capturing one key feature of the EMU and its enlargement, i.e. the fact that the EMU includes several countries - initially eleven. At the same time, it emphasizes how a group of small open countries tends to generate stronger externalities than a single large open economy. This result is potentially relevant even outside the New-Keynesian literature and independently of the specific externality here considered, since it makes clear that the behaviour of the small open or big economy policy makers can generate quite different aggregate effects. Indeed, in our setting the welfare gains of a currency area formed by small open economies are generally larger than those of a monetary union formed by big economies. Intuitively, when economies are small, policy makers take as given what happens in the rest of the world, disregarding completely how their independent policies jointly affect the global economy and the efficient use of the world's resources. By contrast, policy makers of big economies internalize to a large extent the impact of their decisions on the world aggregate outcomes.

The framework of our analysis is a standard New-Keynesian open economy model in which the world is split into two areas, $H$ and $F$. In each area, there is a continuum of small open regions. Each region produces a bundle of differentiated goods. The trade elasticity is allowed to be different from one, to nest the cases in which home and foreign bundles are both substitutes and complements. Results are always shown for different values of this elasticity, since it plays a crucial role in determining the strength and the direction of the terms-of-trade externality 99

In this setup, we consider three different policy regimes $(A, B$ and $C)$. Under regime $A$, in area $H$ exchange rates are flexible and each small open economy has its own autonomous central bank; by contrast, in area $F$ all regions share a common

to anti-inflationary policies. However, the credibility of the monetary authorities can be equally enhanced in other ways - for example by reinforcing central banks' independence and their mandate to pursue price stability - which do not imply renouncing to an important policy instrument for macroeconomic stabilization.

${ }^{7}$ See e.g. Corsetti and Pesenti (2001), Corsetti and Pesenti (2005), Pappa (2004), Benigno and Benigno (2003), Benigno and Benigno (2006), Benigno and Benigno (2008) and De Paoli (2009a).

${ }^{8} \mathrm{As}$ Corsetti, Dedola and Leduc (2010) underlined on page 915, the empirical relevance of the termsof-trade externality as a motive shaping optimal monetary policies in open economies is an open issue. They also mention how, in the past, the debate on this issue has been influenced to some extent by the corresponding debate - and the possible skepticism - in the trade literature on the optimal tariff argument (an argument going back to Johnson (1953), but more recently put forward by, for instance, Grossman and Helpman (1995) and Bagwell and Staiger (1999), who use it to motivate the need for trade agreements). Interestingly, recently there have been several empirical studies in the trade literature (e.g. Broda, Limão and Weinstein (2008) and Bagwell and Staiger (2011)) finding strong support for the idea that countries try to improve the terms of trade in their favor, since, for instance, open economy policy makers systematically set higher tariffs in those sectors where they have more market power. Note, however, that within the WTO using trade policies strategically is difficult and therefore countries may try to use other policy instruments to affect their terms of trade. For example, Epifani and Gancia (2009) explain the relationship between government size and openness in the light of the incentive of non-cooperative fiscal authorities to improve the terms of trade, grounding their results on robust empirical evidence. In conclusion, this new evidence corroborates the empirical relevance of the terms-of-trade externality as a motive driving open economy policy maker decisions.

${ }^{9}$ For a discussion see Tille (2001), Obstfeld and Rogoff (2002), Benigno and Benigno (2003), Pappa (2004) and Corsetti et al. (2010). 
currency and monetary policy is delegated to a single authority (e.g. FED). Under regime $B$ there is a single currency in each area and monetary policy is under the control of two independent central banks (e.g. ECB and FED). Finally, under regime $C$ there is a common central bank for the world economy. Moreover, in all regimes monetary policies are chosen under commitment and are optimal from the timeless perspective 10

Under both regimes $A$ and $B$, optimal policies are biased by the desire of the monetary authorities to affect the terms of trade in their favor. This incentive stems from a free riding problem. Through the manipulation of their terms of trade, open economy policy makers try to increase domestic leisure or consumption at other countries' expense. This incentive is common to the policy makers of both large and small open economies. However, the difference in size of these economies shapes their optimal monetary conduct. When the economy is small, its central bank considers its policy decisions and the performance of the country as irrelevant for the behavior of the aggregate economy. As a consequence, from the small open economy's point of view, strategically manipulating the terms of trade has effects exclusively on domestic output, while leaving the rest of the world unaffected. In equilibrium, however, the opposite is true: since the group of small open economies is large, aggregate distortions are substantial. Indeed, the incentive to try to manipulate the terms of trade in their favor jointly with the inability to internalize the effects of their decisions on the world economy pushes small country policy makers to sharply deviate from the Pareto optimum and to shift inefficiently their inflation-output stabilization trade-off. For this reason, small open economy central banks are more prone to adopt highly inflationary policies that generate strong negative externalities. In contrast, when the economy is big, even if they do not internalize the effects of their policies on other countries' welfare, policy makers take into account the impact of their decisions on the world economy equilibrium outcome. They, thus, disagree on how much to produce and consume individually and they try to manipulate their terms of trade by affecting domestic and foreign outputs in opposite directions to allow domestic households to enjoy relatively more leisure or consumption. Nevertheless, they take into account the feedback effects of their policies stemming from the other area and they recognize the importance of using the resources available in the world economy efficiently. This is why large economy central banks tend to adopt monetary policies which are much less inflationary than those of the small open economy policy makers.

The differences in the conduct of monetary policies explain the differences in outcomes across policy regimes. Under regime $B$, policy makers of areas $H$ and $F$ are exactly symmetric. Both of them generate negative spillovers between areas. Hence, being under regime $C$ instead of $B$ eliminates these externalities. However, independently of the trade-elasticity value, this welfare benefit is always outweighed by the costs due to the impossibility of properly stabilizing area-specific shocks. This result suggests that adopting a common currency for two large economies like the U.S. and the eurozone is not desirable. Conversely, under regime $A$, while the common central bank in area $F$ generates aggregate externalities only between areas, monetary policy makers of the small open economies internalize the spill-over effects neither within nor across areas. As a consequence, for values of the trade elasticity above 1.8, there are welfare benefits - which can be substantial ${ }^{11}$ - for the households living in areas $H$ and $F$ not only from being under regime $B$ instead of $A$, but also from being under regime $C$

\footnotetext{
${ }^{10}$ See Woodford (2003), Benigno and Woodford (2005) and Benigno and Woodford (2012).

${ }^{11}$ Especially if compared with those found in previous studies on monetary policy coordination (e.g. Obstfeld and Rogoff (2002)) and in the business cycle literature (e.g. Lucas (1987) and Lucas (2003)).
} 
instead of $A$. These findings suggest that for a group of small open economies it can pay to form (or enlarge) a monetary union, since there can be a substantial improvement in the conduct of the monetary policy once this is delegated to one single authority. This authority, as a big player in the world economy, recognizes how to use monetary policy more efficiently since it can better foresee the aggregate macroeconomic consequences of its policy decisions.

This paper is organized as follows. Section 2 describes the basic set up and characterizes the Pareto-efficient allocation. Section 3 discusses the steady state distortions, the welfare approximations and the optimal policies under the different regimes. Section 4 reports the results on the welfare evaluation and Section 5 provides a discussion of the possible extensions.

\section{The basic framework}

The world consists of a continuum of small open regions indexed by $i \in[0,1] 12$ The regions are split into two areas $-H$ and $F$ - of equal size. In area $H$, there is a continuum of regions indexed by $i \in\left[0, \frac{1}{2}\right)$, which are independent countries. Area $F$ consists of regions indexed by $i \in\left[\frac{1}{2}, 1\right]$, which belong to a monetary union. In each region $i$, households consume a bundle that includes all the goods produced in the world economy and supply a continuum of imperfectly substitutable labor services which are immobile across both regions and areas. The elasticity between domestic and foreign goods is different from one. Each region produces a continuum of imperfectly substitutable goods using all the labor services available in the domestic economy. There is no capital. Good prices adjust according to a staggered mechanism à la Calvo. Moreover, there are complete financial markets and the model features perfect pass-through since the law of one price holds ${ }^{13}$ However, even if all good prices are set in the domestic currency, there are deviations from purchasing power parity since preferences exhibit home bias for both the domestically produced goods and the goods produced within the area to which the small open economy belongs. For the sake of brevity, in this section we discuss the log-linear approximation of the model, while its full description can be found in Appendix $\mathrm{A}{ }^{14}$ Table 1 lists the equilibrium equations for the regions belonging to area $H$. Symmetric conditions can be stated for the regions that belong to area $F$. The variables $\hat{c}_{t}^{i}, \hat{c}_{H, t} \equiv 2 \int_{0}^{\frac{1}{2}} \hat{c}_{t}^{j} d j$ and $\hat{c}_{F, t} \equiv 2 \int_{\frac{1}{2}}^{1} \hat{c}_{t}^{j} d \sqrt{15}$ denote the log-deviations of consumption in region $i$ and aggregate consumption in area $H$ and $F$, while $\hat{y}_{t}^{i}, \hat{r}_{t}^{i}, \hat{s}_{i H, t}$ and $\hat{s}_{i F, t}$ stand for the log-deviations of domestic output, the nominal interest rate and the terms of trade of region $i$ with respect to area $H$ and $F$ respectively 16 Moreover, $\widehat{m c}_{t}^{i}, \pi_{i H, t} \hat{e}_{i H, t}$ and $\hat{e}_{i F, t}$ represent the log-deviations of region $i$ firms' real marginal cost, producer price inflation and the nominal exchange rate of region $i$ relative to a common unit of account of area $H$ and $F$. We allow for two types of region-specific shocks: a productivity shock denoted by $\hat{a}_{t}^{i}$ and a wage-mark-up shock $\hat{\mu}_{t}^{i}$ which induces exogenous fluctuations in the wedge between the real wage and

\footnotetext{
${ }^{12}$ This model generalizes the framework layout by Galí and Monacelli (2005).

${ }^{13}$ We discuss the implications of these two assumptions for our main results in more detail in Section 5 .

${ }^{14}$ See also Forlati (2012).

${ }^{15}$ As a general notation, given the variable $X_{t}^{j}, \hat{x}_{t}^{j} \equiv \log X_{t}^{j}-\log X^{j}$ is the $\log$-deviation of $X_{t}^{j}$ from the steady state, while $\hat{x}_{H, t} \equiv 2 \int_{0}^{\frac{1}{2}} \hat{x}_{t}^{j} d j$ and $\hat{x}_{F, t} \equiv 2 \int_{\frac{1}{2}}^{1} \hat{x}_{t}^{j} d j$ are the average area log-deviations from the steady state. Moreover, $\Delta \hat{x}_{t}^{i}$ stands for $\hat{x}_{t}^{i}-\hat{x}_{t-1}^{i}$.

${ }^{16}$ As standard in the open macro literature, the terms of trade are defined as the aggregate price of imported goods relative to the aggregate price of the exported goods.
} 


$$
\begin{aligned}
& \pi_{i, t}=\lambda \widehat{m c}_{t}^{i}+\beta E_{t}\left\{\pi_{i, t+1}\right\} \\
& \widehat{m c}_{t}^{i}=\varphi \hat{y}_{t}^{i}+\sigma \hat{c}_{t}^{i}+\left(\alpha_{b}-\alpha_{s}\right) \hat{s}_{i H, t}+\left(1-\alpha_{b}\right) \hat{s}_{i F, t}-(1+\varphi) \hat{a}_{t}^{i}+\hat{\mu}_{t}^{i} \\
& \hat{y}_{t}^{i}=\hat{c}_{t}^{i}+\left[\frac{1-\delta_{b}}{\sigma\left(2 \gamma_{b}-1\right)}-\frac{1-\delta_{s}}{\sigma \gamma_{s}}\right] \hat{s}_{i H, t}-\frac{1-\delta_{b}}{\sigma\left(2 \gamma_{b}-1\right)} \hat{s}_{i F, t} \\
& \hat{s}_{i H, t}=-\sigma \gamma_{s}\left(\hat{c}_{H, t}-\hat{c}_{t}^{i}\right) \\
& \hat{s}_{i F, t}=-\sigma \gamma_{s}\left(\hat{c}_{H, t}-\hat{c}_{t}^{i}\right)-\sigma\left(2 \gamma_{b}-1\right)\left(\hat{c}_{F, t}-\hat{c}_{H, t}\right) \\
& r_{t}^{i}-\rho-E_{t}\left\{\pi_{i, t+1}\right\}=\sigma E_{t}\left\{\Delta \hat{c}_{t+1}^{i}+\left(\gamma_{b}-\gamma_{s}\right)\left(\Delta \hat{c}_{H, t+1}-\Delta \hat{c}_{t+1}^{i}\right)+\left(1-\gamma_{b}\right)\left(\Delta \hat{c}_{F, t+1}-\Delta \hat{c}_{t+1}^{i}\right)\right\} \\
& \Delta e_{i H, t}+\pi_{H, t}-\pi_{i, t}=-\sigma \gamma_{s}\left(\Delta \hat{c}_{H, t}-\Delta \hat{c}_{t}^{i}\right) \\
& \Delta e_{i F, t}+\pi_{F, t}-\pi_{i, t}=-\sigma \gamma_{s}\left(\Delta \hat{c}_{H, t}-\Delta \hat{c}_{t}^{i}\right)-\sigma\left(2 \gamma_{b}-1\right)\left(\Delta \hat{c}_{F, t}-\Delta \hat{c}_{H, t}\right)
\end{aligned}
$$

Table 1: Equilibrium conditions of region $i$ with $i \in\left[0, \frac{1}{2}\right)$.

the marginal rate of substitution between consumption and leisure. The underlying parameters of the model are described in Table 3 in the appendix. In Table1, equation (1) is the New-Keynesian Phillips curve which results from the Calvo mechanism. As usual, current domestic inflation depends on expectations of future domestic inflation and of the current real marginal cost. In the case of small open region $i$, the real marginal cost is equal to the real wage expressed in terms of domestic prices over the marginal product of labor, i.e., $\widehat{m c}_{t}^{i} \equiv \hat{w}_{t}^{i}-\hat{p}_{t}^{i}-\hat{a}_{t}^{i}$. By using the fact that the real wage in terms of consumer prices is set as a mark-up over the marginal rate of substitution between consumption and labor it can then be shown that in equilibrium $\widehat{m c}_{t}^{i}$ is given by equation (2). Equation (3) represents the aggregate demand that in this economy sums up the demands of domestic and foreign households for home produced goods and is critically affected by movements in the terms of trade. Conditions (4) and (5) are a direct consequence of assuming complete financial markets and incorporate the perfect risk sharing between home and foreign households. Finally, equation (6) is the IS curve that follows from the Euler equation, whereas (7) and (8) determine the fluctuations in the nominal exchange rates of region $i$. Notice that under regimes $B$ and $C$, when $e_{i H, t}=1$ and $e_{i F, t}=1$, equations (7) and (8) can be interpreted as a constraint imposed by the adoption of a common currency according to which, in response to asymmetric shocks, the terms of trade cannot adjust instantaneously because of the sluggish price adjustment and the fixed exchange rates. Differently, under regime $A$ in area $H$, when there is monetary autonomy, the fluctuations in the nominal exchange rates ensure that conditions (7) and (8) are always satisfied. The equations in Table 1 determine the small open economy equilibrium given domestic shocks and area $H$ and $F$ aggregate consumption. Integrating these conditions allows us to recover the aggregate equilibrium equations for area $H$ as stated in Table 2, In fact, conditions (9), 10), 11), 12 and (13) represent the aggregate Phillips curve, the equation determining the aggregate firms' marginal cost, the risk sharing condition across areas, the aggregate demand and IS curves for area $H$. Symmetric conditions apply to area $F$.

Before moving to the next section, we discuss briefly the differences between the market equilibrium and the Pareto-efficient allocation in our model. In the absence of mark-up shocks, our framework embodies two distortions: the steady-state distortion 


$$
\begin{aligned}
& \pi_{H, t}=\lambda \widehat{m c}_{H, t}+\beta E_{t}\left\{\pi_{H, t+1}\right\} \\
& \widehat{m c}_{H, t}=\varphi \hat{y}_{H, t}+\sigma \hat{c}_{H, t}+\left(1-\alpha_{b}\right) \hat{s}_{H F, t}-(1+\varphi) \hat{a}_{H, t}+\hat{\mu}_{H, t} \\
& \hat{y}_{H, t}=\hat{c}_{H, t}-\frac{1-\delta_{b}}{\sigma\left(2 \gamma_{b}-1\right)} \hat{s}_{H F, t} \\
& \hat{s}_{H F, t}=-\sigma\left(2 \gamma_{b}-1\right)\left(\hat{c}_{F, t}-\hat{c}_{H, t}\right) \\
& r_{H, t}-\rho-E_{t}\left\{\pi_{H, t+1}\right\}=\sigma E_{t}\left\{\Delta \hat{c}_{H, t+1}+\left(1-\gamma_{b}\right)\left(\Delta \hat{c}_{F, t+1}-\Delta \hat{c}_{H, t+1}\right)\right\} \\
& \Delta e_{H F, t}+\pi_{F, t}-\pi_{H, t}=-\sigma\left(2 \gamma_{b}-1\right)\left(\Delta \hat{c}_{F, t}-\Delta \hat{c}_{H, t}\right)
\end{aligned}
$$

Table 2: Aggregate equilibrium conditions of area $H$.

due to monopolistic competition and the dynamic distortion caused by price and output dispersion. Once these distortions are eliminated - which can be achieved by using an appropriate labor subsidy and by completely stabilizing firms' marginal costs in all markets -, the market equilibrium coincides with the Pareto-efficient allocation. In Appendix B, we retrieve the conditions that characterize the Pareto-efficient optimum. At the same time, using conditions (10) and (11), we can define:

$$
\widehat{m c}_{H, t}^{e} \equiv(\sigma+\varphi) \hat{y}_{H, t}-\frac{\delta_{b}-\gamma_{b}}{2 \gamma_{b}-1} \hat{s}_{H F, t}-(1+\varphi) \hat{a}_{H, t}
$$

as the firms' marginal cost in the absence of mark-up shocks, where the suffix $e$ stands for efficient ${ }^{17}$ A symmetric definition applies to $\widehat{m c}_{F, t}^{e}$, the efficient firms' marginal cost in area $F$. Indeed, it can be shown that stabilizing such costs by setting

$$
\widehat{m c}_{H, t}^{e}=0 \quad \widehat{m c}_{F, t}^{e}=0
$$

ensures, jointly with the equilibrium conditions $(11),(12)$ and its foreign counterparts, that the average output fluctuations mimic those of the efficient allocation. Intuitively, when a technology shock occurs and the firms' marginal costs are held constant, the dynamic distortion due to price stickiness is corrected and the average area fluctuations in the marginal rates of substitution and transformation between consumption and labor are equal.

\section{Welfare}

As anticipated in the introduction, this paper assesses the costs and benefits of a monetary union by comparing, in terms of welfare, three policy regimes. Under regime

\footnotetext{
${ }^{17}$ Regarding condition $[15)$, recall that $\delta_{b}-\gamma_{b}=\left(\gamma_{b}-\alpha_{b}\right)(\eta \sigma-1)$. As a result, the impact of the termsof-trade movements on firms' marginal cost depends critically on whether domestic and foreign goods are substitutes or complements in the utility - i.e., on whether the trade elasticity $\eta$ is greater or smaller than the intertemporal elasticity of substitution $1 / \sigma$. In fact, the parameter $\eta$ governs an intratemporal effect: the higher is $\eta$ the more domestic and foreign households shift the composition of their consumption bundle in response to a change in the terms of trade. By contrast, the parameter $\sigma$ governs an intertemporal effect: the higher is $\sigma$, the more domestic and foreign consumers are inclined to change their borrowing and lending decisions in response to exogenous shocks in order to smooth consumption across periods. These results are well known in the open macro literature. For a discussion, see Galí and Monacelli (2005) and Corsetti et al. (2010).
} 
$A$, there is a common currency in area $F$, while countries in area $H$ retain their own central banks; under regime $B$, there are two monetary unions, one in area $F$ and the other one in area $H$. Under regime $C$, there is a single authority that sets the interest rate for the world economy as a whole.

In order to solve the optimal monetary policy problems, we make the following assumptions. Independently of the policy regime, monetary authorities are benevolent, take as given other policy makers' choices and can commit credibly to past and future promises. In other words, policies are optimal from the timeless perspective. As in Benigno and Benigno (2006), policy makers' strategies of the policy game under regimes $A$ and $B$ are specified in terms of the entire path of inflation defined as a time-varying function of the shocks hitting the economy ${ }^{18}$ Thus when maximizing domestic utility at time 0 , these authorities commit credibly to implement the desired state-contingent path of inflation, taking as given the state-contingent path of inflation chosen by foreign policy makers. ${ }^{19}$ Under these hypotheses, we use the linear-quadratic approach pioneered by Benigno and Woodford (2005) and Benigno and Woodford (2012) to determine the optimal policies under the different regimes. ${ }^{20}$

\subsection{The steady-state distortion}

As a first step to implement the linear quadratic approach, we show the following result ${ }^{21}$ Under the assumption of equal employment subsidies across regions, there exists a symmetric deterministic steady state at which zero inflation is a Nash equilibrium of the Ramsey policy game under both regimes $A$ and $B$. A similar finding arises under regime $C$ At the zero-inflation steady state $Y=C=(1-\tilde{\tau})^{-\frac{1}{\sigma+\varphi}}$ where $Y$ and $C$ represent the steady-state levels of output and consumption, while $\tilde{\tau} \equiv 1-(1-\tau)(1+\mu) \frac{\varepsilon}{\varepsilon-1}$. Then, $(1-\tilde{\tau}) M R S=(1-\tilde{\tau}) C^{\sigma} Y^{\varphi}=1=M R T$. In other words, $\tilde{\tau}$ determines the steady-state wedge between the marginal rates of substitution and transformation between consumption and leisure.

Given their different objectives, the policy makers of the small open economies and of the monetary unions have different incentives and different ideas about what is the efficient steady-state level of domestic output.

Consider first the case of a cooperative policy maker. Not surprisingly, at the deterministic steady state, this policy maker finds it optimal to choose $\tilde{\tau}=1-(1-$ $\tau)(1+\mu) \frac{\varepsilon}{\varepsilon-1}=0$ so that $Y_{w}=1$. With this policy, she manages to implement the Pareto optimum, offsetting the monopolistic distortions in both the labor and the goods markets and closing completely the wedge between marginal rates of substitution and transformation. Then, we can define $\Phi_{w} \equiv \tilde{\tau}$ as a parameter that governs the steadystate distortion from the world economy policy maker's viewpoint.

Consider now the case of the small open economy $i$. The efficient steady state from the small open policy maker's perspective is equal to: 23

\footnotetext{
${ }^{18}$ Namely, we study the open-loop Nash equilibrium.

${ }^{19}$ Notice that given this assumption, under regime $A$, small open economy central banks take as given all the aggregate variables. Intuitively, if the economy is infinitesimally small, its performance cannot influence aggregate variables.

${ }^{20}$ Actually, it would be difficult to compute these policies using standard perturbation methods, since the economy is framed as a continuum of small open regions.

${ }^{21}$ See the online appendix for a discussion of the zero-inflation steady state and also of other accessory results like the welfare approximations, the welfare-relevant targets and the optimal policy problems.

${ }^{22}$ For a formal proof, see Benigno and Benigno (2006).

${ }^{23} \mathrm{On}$ the formal derivation of this result and the following one for the case of the big economy policy maker see Forlati (2012).
} 


$$
Y_{s}=\delta_{s}^{\frac{-1}{\sigma+\varphi}}
$$

where $\delta_{s} \equiv \gamma_{s} \eta \sigma+\alpha_{s}(1-\eta \sigma)$ can be interpreted as the elasticity of region $i$ output to region $i$ consumption. According to (17), $\tilde{\tau}_{s}=1-\delta_{s}$ is the optimal labor subsidy that decentralizes the correspondent steady state allocation as a market equilibrium. Then, $\Phi_{s} \equiv \tilde{\tau}-\tilde{\tau}_{s}$ can be picked as a parameter that measures the steady-state distortion from the small open economy's perspective.

Condition (17) also points out how the small open economy policy makers do not aim to reach the Pareto-efficient steady state at which the monopolistic distortions are exactly eliminated unless $\delta_{s}=1$. As long as $\delta_{s}>1\left(\delta_{s}<1\right)$, they would prefer a lower (higher) level of steady-state production. Consider, for instance, the parametric configuration $\eta \sigma>1$ where domestic and foreign goods are substitutes in the utility and $\delta_{s}>1$. In this case, the authorities of small open economies try to lower output in order to improve the terms of trade and to externalize labor effort at the other countries' expense. Indeed, as the terms of trade ameliorate, consumers at home borrow more (intertemporal effect), enjoy more leisure and possibly reduce their demand for domestic goods since foreign goods have became cheaper (intratemporal effect). Domestic consumption falls relative to foreign consumption. However, its fall is dampened by the rise in borrowing and in the demand for goods produced abroad. Hence, domestic consumption decreases less than output. As a consequence, the rise in leisure due to the reduction in the labor supply more than compensates households for the fall in consumption generated by the terms-of-trade improvement.

Suppose now that $\frac{\alpha_{s}}{1+\alpha_{s}}<\eta \sigma<1$. In this case, $\delta_{s}$ is still greater than one. Intuitively, even if home and foreign goods are complements in the utility, consumers find it optimal to borrow more. In this way, they can dampen the reduction of the overall expenditure for consumption reducing their labor supply at the same time. Still, home consumption falls less than output and small open economy policy makers try to improve their terms of trade. However, when $\eta \sigma<\frac{\alpha_{s}}{1+\alpha_{s}}-$ and then $\delta_{s}<1-$, home and foreign goods are strong complements and this incentive is reversed. Small country authorities seek to increase domestic output. The intuition for this result is provided by Corsetti et al. (2010) in Section 5.1. As domestic and foreign goods are complements in the utility the marginal utility, from consuming domestic goods increases with the consumption of foreign goods. Then, domestic policy makers seek to import more foreign goods by raising domestic production. Despite the implied terms-of-trade worsening, domestic consumption of both home and foreign produced goods increases, more than compensating the reduction in leisure in the utility. Finally, if $\delta_{s}=1, \Phi_{s}=\Phi_{w}$. Then, the steady-state level of output is efficient from the small open economy viewpoint and coincides with the Pareto-efficient level i.e., $Y_{s}=Y_{w}$.

In contrast, in the case of the policy maker of the monetary union, the desired level of steady-state output in the domestic economy is determined as:

$$
Y_{b}=\left[1-\frac{\left(1-\delta_{b}\right)(\sigma+\varphi)}{\left(\delta_{b} \varphi+\gamma_{b} \sigma\right)}\right]^{\frac{-1}{\sigma+\varphi}}
$$

This allocation can be achieved as market equilibrium by choosing a labor subsidy of $\tilde{\tau}_{b}=\frac{\left(1-\delta_{b}\right)(\sigma+\varphi)}{\left(\delta_{b} \varphi+\gamma_{b} \sigma\right)}$ where $\delta_{b} \equiv \gamma_{b} \eta \sigma+\alpha_{b}(1-\eta \sigma)$. At the same time, we can define: $\Phi_{b} \equiv \tilde{\tau}^{-} \tilde{\tau}_{b}$ as the analogue of the parameters $\Phi_{w}$ and $\Phi_{s}$ for the case of the big economy.

According to (18), even in such a case, policy makers seek to manipulate the terms of trade to their own advantage. Yet differently from the case of the small open economy, 


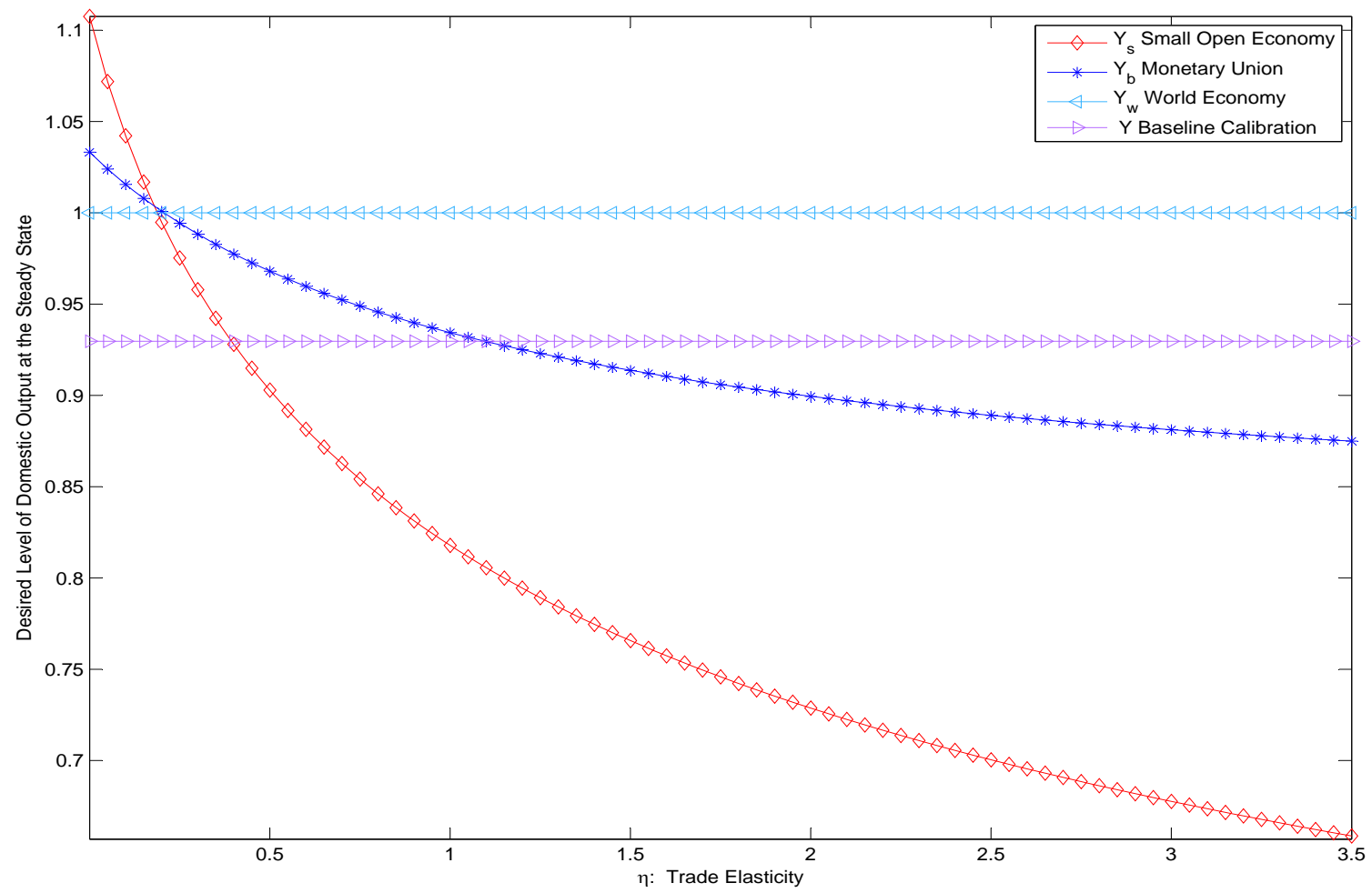

Figure 1: Desired level of steady state domestic output as a function of the trade elasticity $\eta$ under complete markets.

the key parameter that governs this incentive is $1-\delta_{b}$. Depending on whether $\delta_{b}$ is greater or smaller than 1, policy makers of the big economies would like to undersubsidize or over-subsidize labor, with respect to what would be Pareto efficient. Again when $\delta_{b}=1$ there is no incentive to manipulate the terms of trade. Thus, in this case domestic output is distorted from the big economy viewpoint only when the steady state is not Pareto efficient, i.e., $Y_{b} \neq Y_{w}$.

To summarize the above discussion, Figure 1 plots the desired level of domestic output ${ }^{24}$ for the three cases considered - namely, the cases of the world, the small open economy and the big economy policy maker - as a function of the trade elasticity $\eta$ and using the baseline parameterization: i.e., $\alpha_{s}=0.6, \alpha_{b}=0.85 \sigma=2$ and $\varphi=3$. The line with triangles shows the level of steady-state output under the baseline parameterization.

For most values of $\eta$, policy makers of both small and big economies want to undersubsidize labor to improve their terms of trade. However, this incentive is significantly stronger for the small open economy policy makers. For instance, when $\eta=2, Y_{b}$ and $Y_{s}$ are respectively $11.5 \%$ and $27.13 \%$ lower than $Y_{w}$, the Pareto efficient level of output. The reasons for this outcome are threefold. First of all, bigger countries are less open. As a consequence, the incentive of their policy makers to improve the terms of trade is weaker. Secondly, big economy authorities realize that they hold monopoly power only on the terms of trade between areas and they internalize the external effects produced within the monetary union. Finally, they take into account the impact of their policies on the foreign economy. All these motives contribute to the weakening of the desire to influence the terms of trade.

Summing up, the difference in size between small and big countries affects the strength of the incentive to generate externalities at the steady state. Under the baseline parameterization, for almost all the values of the trade elasticity, the desired

\footnotetext{
${ }^{24} \mathrm{We}$ could have alternatively shown the level of the desired subsidies.
} 
steady-state level of domestic output is closer to Pareto efficiency in the case of the monetary union. As will become evident in the next sections, this difference in incentives is key to explaining even the differences in optimal policies over the business cycle. Indeed, if the steady state is distorted from their own perspective, monetary policy makers seek to manipulate household and firm behavior over the business cycle in order to drive what we call the per period output and the per period terms of trade (i.e., the expected level of output and of the terms of trade) towards their desired levels.

\subsection{The benchmark: the case of cooperation}

The second step of the linear quadratic approach requires us to retrieve a purely quadratic approximation to the monetary authorities' objectives, by using the secondorder approximation to the structural equations and then to express this approximation in deviations from the welfare-relevant targets so as to interpret it as a loss function. In this section, we consider the benchmark case of cooperation in which there is a common authority that maximizes the world welfare 25 As shown in the appendix available online, we can approximate the objective of the cooperative policy maker as:

$$
\begin{aligned}
& \frac{1}{1-\tilde{\tau}} \sum_{t=0}^{\infty} \beta^{t} \frac{1}{2} E_{0}\left[\varpi_{11, w} \int_{0}^{\frac{1}{2}}\left(\tilde{s}_{i H, t}^{w}\right)^{2} d i+\varpi_{11, w} \int_{\frac{1}{2}}^{1}\left(\tilde{s}_{i F, t}^{w}\right)^{2} d i+\varpi_{12, w}\left(\tilde{y}_{H, t}^{w}\right)^{2}\right. \\
& \left.+\varpi_{12, w}\left(\tilde{y}_{F, t}^{w}\right)^{2}+\varpi_{13, w}\left(\tilde{s}_{H F, t}^{w}\right)^{2}+\varpi_{4, w} \int_{0}^{1}\left(\pi_{i, t}\right)^{2} d i\right]+t . i . p .
\end{aligned}
$$

where $\varpi_{11, w}, \varpi_{12, w}$ and $\varpi_{13, w}$ depend on the structural parameters of the model, and t.i.p. stands for "terms independent of policies". Moreover, in (19) we use the convention by which $\tilde{x}_{t}^{w} \equiv \hat{x}_{t}-\hat{x}_{t}^{w}$, namely, $\tilde{x}_{t}^{w}$ is the gap between the variable $\hat{x}_{t}$ and the corresponding target of the world policy maker $\hat{x}_{t}^{w}$. Consistently with the open macro literature, for instance with Benigno and Benigno (2006) and Corsetti et al. (2010), the welfare loss in (19) is expressed as a function of regional inflations, areaspecific output gaps and terms-of-trade gaps between areas and between regions and areas. Inflation and terms-of-trade gaps account for the inefficient dispersion of output across firms, and across regions and areas respectively. If all these gaps were closed, the welfare loss would be zero and the equilibrium allocation would coincide with the welfare-relevant target. In general, this target can be conceived as the allocation that a policy maker would choose, taking into account the steady-state distortion due to monopolistic competition, or a distortive labor subsidy, but abstracting from the dynamic distortion generated by firm price dispersion. For this reason its analytical expression helps to disentangle what drives policy makers' incentives.

In the case of cooperation, the target of the cooperative authority satisfies the following conditions: ${ }^{26}$

$$
\left[1-\zeta_{w}(\varphi+1)\right] \widehat{m c}_{H, t}^{e, w}=\zeta_{w}(\varphi+1) \hat{\mu}_{H, t} \quad\left[1-\zeta_{w}(\varphi+1)\right] \widehat{m c}_{F, t}^{e, w}=\zeta_{w}(\varphi+1) \hat{\mu}_{F, t}
$$

\footnotetext{
${ }^{25}$ This approximation of the welfare will then be used to retrieve the objective of the central bank of the world monetary union in regime $C$.

${ }^{26}$ See the online appendix for the full set of equations that determine the target of the cooperative policy maker. For the sake of simplicity, we limit the discussion of the target of the cooperative authority to the average-area variables. However, it can be shown that similar conditions hold for single regions:
}

$$
\left[1-\zeta_{w}(\varphi+1)\right] \widehat{m c}_{i, t}^{e, w}=\zeta_{w}(\varphi+1) \hat{\mu}_{t}^{i}
$$


where $\widehat{m c}_{H, t}^{e, w}$ and $\widehat{m c}_{F, t}^{e, w}$ are defined consistently with (15). From (21), we draw the following conclusions about the goals of the cooperative authority ${ }^{27}$

1. The trade-off. The cooperative monetary policy maker faces a trade-off between stabilizing completely the firms' marginal costs at their efficient level (i.e., $\widehat{m c}_{H, t}^{e, w}=$ 0 and $\left.\widehat{m c}_{F, t}^{e, w}=0\right)$ and allowing $\widehat{m c}_{H, t}^{e, w}$ and $\widehat{m c}_{F, t}^{e, w}$ to fluctuate in response to markup shocks.

2. The weights of the trade-off and the steady-state distortion. The coefficients $1-$ $\zeta_{w}(\varphi+1)$ and $\zeta_{w}(\varphi+1)$ correspond to the relative weights attached to the tradeoff and depend critically on the $\Phi_{w}$, the parameter that governs the steady-state distortion. In fact, since $\zeta_{w}=\frac{\Phi_{w}}{(\sigma+\varphi)}, \zeta_{w}=0$ if and only if $\Phi_{w}=0$. As a result, if the steady state is Pareto efficient (i.e., $\Phi_{w}=0$ ) we go back to the standard finding of closed economy literature - emphasized, among others, by Woodford (2003) and Galí (2008) - and completely stabilizing firms' marginal costs at their efficient level is the target of the monetary policy maker.

3. The case for price stability. Independently of whether the steady state is distorted or not, if shocks are only to technology, strict-inflation targeting is optimal. Intuitively, even when $\Phi_{w} \neq 0$, the monetary policy maker does not try to correct not even partially - the steady-state distortions because the welfare gains derived from the improvement of per period output towards efficiency are exactly offset by the costs associated with firm output dispersion.

4. Mark-up shocks. Under mark-up shocks, the monetary authority is willing to allow $\widehat{m c}_{H, t}^{e, w}$ and $\widehat{m c}_{F, t}^{e, w}$ to fluctuate over the cycle to the extent to which the steady state is distorted. In particular, if the per period output is inefficiently low - i.e., if $\Phi_{w}<0-$, the monetary policy maker wants output to negatively co-move with mark-up shocks. As a result, she changes her inflation output stabilization trade-off and under-stabilizes output - namely, she stabilizes it less than what she would do if the steady state were efficient. The higher $\Phi_{w}$, the stronger this incentive is.

At first, the fourth result is quite puzzling: we might expect that the central bank would aim to completely stabilize output and consumption (as in fact it is willing to do when the steady state is efficient). Instead, it wants output and consumption to co-move with these shocks. The underlying reason for this behavior can be understood by considering the expected value of the labor supply schedule in its closed economy counterpart in the absence of shocks to technology, namely:

$$
E\left\{\frac{W_{t}}{P_{t}}\right\}=E\left\{Y_{t}^{\varphi+\sigma}\right\} E\left\{\left(1+\mu_{t}\right)\right\}+\operatorname{Cov}\left\{Y_{t}^{\varphi+\sigma}\left(1+\mu_{t}\right)\right\} .
$$

According to (22), the lower the covariance between mark-up shocks and output, the lower is the per period output for a given level of per period real wage. This condition then explains why the cooperative authorities have an incentive to manipulate strategically the effects of uncertain mark-up shocks on households' behavior. By providing worse - or better - insurance against these shocks the cooperative central bank can induce households to raise - or reduce - their average labor effort. If, for instance, per period output is inefficiently low, policies that raise the negative co-movements between output and mark-up shocks have beneficial welfare effects: they shift the average labor supply curve downward, allowing for an efficient increase in the expected level of production.

\footnotetext{
${ }^{27}$ Most of these conclusions are the same as those of Benigno and Benigno $(2006)$.
} 
As a final last step of the linear quadratic approach, we use 19 to set up the policy problem and recover the optimal policy under regime $C$. Then, in the tradition of the macro literature ${ }^{28}$ we rearrange the related first-order conditions to obtain:

$$
\varpi_{4, w}\left(\frac{1}{2} \pi_{H, t}+\frac{1}{2} \pi_{F, t}\right)+\frac{\varpi_{12, w}}{\lambda(\sigma+\varphi)}\left(\frac{1}{2} \Delta \tilde{y}_{H, t}^{w}+\frac{1}{2} \Delta \tilde{y}_{F, t}^{w}\right)=0
$$

Condition (23) represents the optimal targeting rule for the world currency area. According to this rule (and the aggregate world Phillips Curve), in general, and not surprisingly, the world policy maker faces a trade-off between stabilizing the average world inflation and the average world output gap, a trade-off akin to that highlighted in the closed economy literature by Benigno and Woodford (2005). Consistently with the previous discussion, in the presence of only technological shocks the policy maker of the world currency area completely stabilizes the average world inflation. Conversely, under mark-up shocks she stabilizes inflation only partially, taking into account how the covariance between these shocks and output influences per period output.

\subsection{The case of the small open economy}

As shown in the appendix available online, the objective of the small open economy policy maker of country $i$ in area $H$ can be approximated in terms of output gap, terms-of-trade gaps and inflation as:

$$
\frac{1}{1-\tilde{\tau}} \sum_{t=0}^{\infty} \beta^{t} \frac{1}{2} E_{0}\left[\varpi_{1, s}\left(\tilde{y}_{t}^{i, s}\right)^{2}+\varpi_{11, s}\left(\tilde{s}_{i H, t}^{s}\right)^{2}+\varpi_{12, s}\left(\tilde{s}_{i F, t}^{s}\right)^{2}+\varpi_{4, s}\left(\pi_{i, t}\right)^{2}\right]+\text { t.o.c. }
$$

where $\varpi_{1, s}, \varpi_{4, s}, \varpi_{11, s}$ and $\varpi_{12, s}$ are a function of the model's deep parameters and $\tilde{x}_{t}^{s}$ stands for the deviation of $\hat{x}_{t}$ from the target of the small open economy policy maker, i.e., $\tilde{x}_{t}^{s} \equiv \hat{x}_{t}-\hat{x}_{t}^{s}$. In addition, t.o.c. represents "the terms out of the control" of the monetary authorities and contains both the terms independent of monetary policy and the aggregate variables of areas $H$ and $F$. Beside the variables included, what is crucially different in the welfare approximations $(19)$ and $(24)$ are the weights attached to inflation, output gap and terms-of-trade gaps. These weights embed the policy trade-offs faced by the small open economy central bank and determine its policy target which needs to satisfy the next condition 29

$$
\left[1-\zeta_{s}(\varphi+1)\right] \widehat{m c}_{i, t}^{e, s}=\zeta_{s}(\varphi+1) \hat{\mu}_{t}^{i}+\kappa_{H}^{s} \hat{s}_{i H, t}^{s}+\kappa_{F}^{s} \hat{s}_{i F, t}^{s} .
$$

In $(25), \widehat{m c}_{i, t}^{e, s}$ is the efficient level of firms' marginal cost in country $i$, defined as the small open economy counterpart of (15). Comparing (25) with 20), its analogue for the cooperative case, allows us to stress the following findings:

1. The trade-off. The small open economy policy maker faces a trade-off between: stabilizing firms' marginal cost at its efficient level, affecting the covariance between output and mark-up shocks to drive the per period terms of trade towards its efficient level and manipulating the terms of trade that are relevant from the small open economy's viewpoint over the cycle. The relative strength of these three incentives depends critically on the coefficients $1-\zeta_{s}(\varphi+1), \zeta_{s}(\varphi+1)$ and both $\kappa_{H}^{s}$ and $\kappa_{F}^{s}$ respectively.

\footnotetext{
${ }^{28}$ See Woodford (2003) and Corsetti et al. (2010) among others.

${ }^{29}$ See the online appendix for the full set of equations that determine the target of the small open economy.
} 
2. The weights of the trade-off and the steady-state distortion. As was discussed for the cooperative case, $\zeta_{s}$ is determined by $\Phi_{s}$, the parameter that, in turn, determines the steady-state distortion from the perspective of the policy makers of the small regions. In fact, $\zeta_{s}=\frac{\Phi_{s}}{\delta_{s} \varphi+\gamma_{s} \sigma}$. Then, $\zeta_{s}=0$ if and only if $\Phi_{s}=0$, i.e., the steady state is efficient from the viewpoint of the small open economy. However, differently from the cooperative case, even when $\Phi_{s}=0$, stabilizing marginal cost fluctuations at their efficient level is not the target of regional authorities: they still trade off between this incentive and the desire to influence terms-of-trade volatility to their own advantage. As a result, in general, strict inflation targeting cannot be optimal even when shocks are only to technology and the steady state is not distorted from the small open economy's perspective.

3. The case for price stability. Under the parametric restriction $\eta \sigma=1$, it follows that $\kappa_{H}^{s}=\kappa_{F}^{s}=0$ and the target of the small open economy policy makers in the presence of technological shocks turns out to replicate the flexible-price allocation. This finding is independent of whether the steady-state distortion has been eliminated by an appropriate labor subsidy (i.e., independent of whether $\Phi_{s}=0$ ) and is consistent with the conclusions of the previous literature (see Benigno and Benigno (2003), Galí and Monacelli (2005) and De Paoli (2009a)). Intuitively, when $\eta \sigma=1$, domestic output fluctuations are independent of the terms of trade since the intertemporal and the intratemporal effects exactly compensate and the terms-of-trade movements do not induce domestic households to change their consumption and labor decisions. Then, the policy makers of the small open economies anticipate that they cannot affect aggregate households' behavior by using the terms of trade over the cycle strategically.

4. Mark-up shocks. As in the case of cooperation, the target of the small open economy authorities reacts to domestic mark-up shocks if and only if the steady state is inefficient from the small open economy's perspective (i.e., if $\Phi_{s} \neq 0$ ). More precisely, suppose that the small open region policy maker has an incentive to improve her per period terms of trade (i.e., $\Phi_{s}>0$ ). Then, she can affect the covariance between output and mark-up shocks. The mechanism works exactly as in the case of the cooperative policy maker. By stabilizing output more than inflation 30 in response to mark-up shocks, small country authorities can induce domestic households to lower their per period labor effort. As a result, per period domestic output - which is perceived as too high - can fall, improving the terms of trade.

5. The terms-of-trade volatility. When $\eta \sigma \neq 1$, it follows that $\kappa_{H}^{s} \neq 0$ and $\kappa_{F}^{s} \neq 0$. In other words, if $\eta \sigma \neq 1$, independently of whether the steady state is considered efficient or not, the policy makers of the small open countries are willing to influence the terms of trade over the cycle. Notice that since $\kappa_{H}^{s}$ and $\kappa_{F}^{s}$ depend critically on $\Phi_{s}$, they use the manipulation of the terms-of-trade volatility also to drive the expected levels of the terms of trade and output towards the desired levels 31

Finally, the welfare losses in (24) allows us to formulate the optimal monetary policy problem of the small open economy policy maker. Using the corresponding first-order conditions, we can write the optimal targeting rule of the small open economy policy

${ }^{30}$ as long as $\frac{\delta_{s} \varphi+\gamma_{s} \sigma}{\varphi+1}>\delta_{s}-(1-\tilde{\tau})$.

${ }^{31}$ These incentives are explained more in detail in Forlati (2012). 
maker as follows:

$$
\varpi_{4, s} \pi_{i, t}+\frac{\delta_{s} \varpi_{1, s}}{\lambda\left(\sigma \gamma_{s}+\varphi \delta_{s}\right)} \Delta \tilde{y}_{t}^{i, s}+\frac{\sigma \gamma_{s} \varpi_{11, s}}{\lambda\left(\sigma \gamma_{s}+\varphi \delta_{s}\right)} \Delta \tilde{s}_{i H, t}^{s}+\frac{\sigma \gamma_{s} \varpi_{12, s}}{\lambda\left(\sigma \gamma_{s}+\varphi \delta_{s}\right)} \Delta \tilde{s}_{i F, t}^{s}=0
$$

Condition (26), jointly with the small open economy equilibrium equations, determines the equilibrium allocation under optimal policy. Notice that the difference between this allocation and the target is due exclusively to the additional distortion, the price dispersion, a consequence of the Calvo pricing, the small open economy maker has to cope with under optimal policy. In fact, the incentives discussed in the first part of this section while considering the target in (25) explain the behavior of the small open economy central bank even when implementing the optimal policy. According to (26) and in line with De Paoli (2009a), in general the small open economy policy maker faces a trade-off between stabilizing domestic inflation, output gap and terms-of-trade gaps. This trade-off reflects her desires to manipulate the terms of trade over the business cycle and correct the steady-state distortion from the small open economy's perspective. Only when the $\eta \sigma=1$ and there are only productivity shocks, strictinflation targeting is the optimal rule.

The above discussion makes it clear that the behavior of the small open economy and cooperative policy makers are quite different. However, what will prove to be crucial for our findings is the difference in the perceptions of the steady-state distortions. This difference can explain why for high enough values of trade elasticity, small open policy makers are inclined to engage highly distortionary monetary policies in response to mark-up shocks. The strong incentive to deviate from the efficient level of the per period output shifts inefficiently their inflation-output stabilization trade-off and pushes small open economy central banks to adopt a monetary policy stance which is substantially less aggressive than that of the cooperative policy maker.

\subsection{The case of the big economy}

If there is a monetary union in area $H$, the objective of the monetary policy maker can be approximated in terms of welfare-relevant gaps as:

$$
\frac{1}{1-\tilde{\tau}} \sum_{t=0}^{\infty} \beta^{t} \frac{1}{2} E_{0}\left[\varpi_{15, b}\left(\tilde{y}_{H, t}^{b}\right)^{2}+\varpi_{16, b}\left(\tilde{s}_{H F, t}^{b}\right)^{2}+\varpi_{17, b}\left(\tilde{y}_{F, t}^{b}\right)^{2}+\varpi_{4, b} \pi_{H, t}^{2}\right]+\text { t.o.c. }
$$

where $\varpi_{4, b}, \varpi_{15, b}, \varpi_{16, b}$ and $\varpi_{17, b}$ depend on the fundamental parameters of the model and $\tilde{x}_{t}^{b} \equiv \hat{x}_{t}-\hat{x}_{t}^{b}$ stands for the deviation of the variable $\hat{x}_{t}$ from the target of the area $H$ central bank $\hat{x}_{t}^{b}$. In addition t.o.c., "the terms out of control" of the policy maker, include the state-contingent path of $\pi_{F, t}$ decided by area $F$ policy maker and the differentials between country-specific and average-union variables ${ }^{32}$ To grasp some insights about the incentives driving the policy maker of the monetary union, we use the next expression:

$$
\begin{aligned}
{\left[1-\zeta_{b}(\varphi+1)\right] \widehat{m c}_{H, t}^{e, b} } & =\zeta_{b}(\varphi+1) \hat{\mu}_{H, t}+\kappa_{H}^{b} \hat{s}_{H F, t}^{b} \\
-\left(\zeta_{w}-\zeta_{b}\right)(\varphi+1) \widehat{m c}_{F, t}^{e, b} & =\left(\zeta_{w}-\zeta_{b}\right)(\varphi+1) \hat{\mu}_{F, t}+\kappa_{F}^{b} \hat{s}_{H F, t}^{b}
\end{aligned}
$$

\footnotetext{
${ }^{32}$ Indeed, without loss of generality, we assume that by choosing the average-union inflation, the common central bank cares only about the average performance of the currency area. However, these terms have to be taken into account in the welfare evaluation.
} 
Again $\widehat{m c}_{H, t}^{e, b}$ and $\widehat{m c}_{F, t}^{e, b}$ are defined consistently with 15 . This condition, jointly with the other conditions listed in the online appendix, determines the target of the big economy. By contrasting (28) with its counterparts, (21) and (25), we reach the following conclusions:

1. The trade-off. According to (28), big economy policy makers face a trade-off between: stabilizing the fluctuations of average-area efficient marginal costs, manipulating the covariances between output and mark-up shocks of both areas and influencing the volatility of the terms of trade between areas. The relative strength of these incentives depends critically on the coefficients $1-\zeta_{b}(\varphi+1)$, $\zeta_{b}(\varphi+1), \kappa_{H}^{b},-\left(\zeta_{w}-\zeta_{b}\right)(\varphi+1),\left(\zeta_{w}-\zeta_{b}\right)(\varphi+1)$ and $\kappa_{F}^{b}$.

2. The weights of the trade-off and the steady-state distortion. In the case of the big economy - differently from the cooperative case - the monetary authority of area $H$ attaches different weights to the stabilization of domestic and foreign efficient marginal costs. This is because the per period terms of trade at the symmetric steady state are inefficient from the area $\mathrm{H}$ policy maker's perspective. Indeed, the weight of domestic marginal cost is $1-\zeta_{b}(\varphi+1)$ where $\zeta_{b}=\frac{\Phi_{b}\left(\gamma_{b} \sigma+\delta_{b} \varphi\right)}{(\sigma+\varphi)\left(\left(2 \gamma_{b}-1\right) \sigma+\left(2 \delta_{b}-1\right) \varphi\right)}$ and is determined by $\Phi_{b}$. Then, as long as $\delta_{b}>1$ and $\Phi_{b} \neq 0$, the authority of the monetary union tries to push domestic per period output toward a level that is inefficiently low from the cooperative viewpoint. In contrast, the weight of the foreign marginal cost is $-\left(\zeta_{w}-\zeta_{b}\right)(\varphi+1)$ and corresponds - as long as $\delta_{b}>1$ - to the intention of driving foreign per period output towards an inefficiently high level. In other words, in this case, the policy maker in area $H$ seeks to push domestic and foreign per period output in opposite directions to generate - as long as $\delta_{b}>1-$ an improvement of the cross-area terms of trade. However, the average weight corresponds to that of the cooperative authorities, i.e., $1-\zeta_{b}(\varphi+$ $1)-\left(\zeta_{w}-\zeta_{b}\right)(\varphi+1)=1-\zeta_{w}(\varphi+1)$. Despite the conflicts with other policy makers, the monetary authority of the large economy wishes to make efficient use of the resources available in the world economy.

3. The case for price stability. When $\eta \sigma=1$, it follows that $\gamma_{b}=\delta_{b}$. As a consequence, $\kappa_{H}=0$ and $\kappa_{F}=0$ and $\widehat{m c}_{H, t}^{e, b}=0$ and $\widehat{m c}_{F, t}^{e, b}=0$. Then, under productivity shocks, implementing the flexible-price allocation becomes the target of the common central bank and strict inflation targeting the optimal policy. This result is consistent with other findings in the open macro literature, for instance Benigno and Benigno (2003) and Benigno and Benigno (2006). The intuition is exactly the same as explained for the case of the small open economies. Open economy policy makers internalize that if $\eta \sigma=1$ there is no reason to manipulate the terms of trade because they cannot influence domestic output.

4. Mark-up shocks. Only when $\Phi_{b} \neq 0$ or $-\left(\zeta_{w}-\zeta_{b}\right)(\varphi+1) \neq 0$, the monetary authority has the additional incentive to try to manipulate strategically the covariance between outputs and mark-up shocks: by shifting the average labor supply curves she tries to push domestic and foreign per period outputs towards their efficient levels.

5. The terms-of-trade volatility. When $\eta \sigma \neq 1, \kappa_{H}^{b} \neq 0$ and $\kappa_{F}^{b} \neq 0$ and similarly to small open economy authority, the monetary authority of the area seeks to affect strategically the terms of trade volatility both to drive domestic and foreign output towards the desired levels and to try to decrease the welfare costs of consumption and leisure volatilities.

According to the previous discussion, big countries recognize the importance of an efficient use of the resources available in the world economy. Nevertheless, they disagree 
on how much to produce and consume individually. This free riding problem generates a conflict that translates into the desire to manipulate the terms of trade between areas. Countries wish to generate output differentials to allow domestic households to enjoy relatively more leisure or consumption. This mechanism can even clarify why the size of the economy can shape optimal policy decisions. When the economy is big, policy makers behave strategically: they realize that they can influence the terms of trade by affecting domestic and foreign outputs in opposite directions. At the same time, they internalize the effects that their policies produce on the foreign economy, even if they disregard the effects on foreign household welfare. They take into account, for instance, that when $\eta \sigma>1$, domestic terms of trade improve, not only the demand of domestic households but even that of foreign consumers switches from domestic towards foreign goods, amplifying the effects on output differentials. Differently, in the limiting case of a small economy, the only way monetary policy can manipulate the per period terms of trade in its favor is by affecting per period domestic production. In fact, the economic performance of a small open country is irrelevant for the behavior of the aggregate economy. However, the joint policies of small open regions in one area can produce large business cycle effects on both the domestic and the foreign areas.

Finally, we use the welfare loss in (27) to formulate the optimal monetary policy problem of the area $H$ policy maker. As above, by rearranging the first-order conditions to this problem we obtain:

$$
\varpi_{4, b} \pi_{H, t}+\frac{\varpi_{15, b} \xi_{1}}{\lambda(\sigma+\varphi) \xi_{2}} \Delta \tilde{y}_{H, t}^{b}+\frac{\varpi_{16, b} \sigma\left(2 \gamma_{b}-1\right)}{\lambda \xi_{2}} \Delta \tilde{s}_{H F, t}^{b}+\frac{\varpi_{17, b} \sigma\left(\gamma_{b}-\delta_{b}\right)}{\lambda(\sigma+\varphi) \xi_{2}} \Delta \tilde{y}_{F, t}^{b}=0
$$

where $\xi_{1} \equiv \sigma\left(\gamma_{b}-\delta_{b}\right)+\left(2 \delta_{b}-1\right)(\sigma+\varphi)$ and $\xi_{2} \equiv\left(2 \delta_{b}-1\right) \varphi+\left(2 \gamma_{b}-1\right) \sigma$. Condition (29) represents the optimal targeting rule of the monetary union central bank and jointly with the other equilibrium conditions determines the best response of the policy maker in area $H$ given the state-contingent path of $\pi_{F, t}$. Symmetric conditions can be stated for the foreign area to determine the Nash-equilibrium policies under regimes $A$ and $B$. The interpretation of the policy prescription in $(29)$ is quite clear: once the distortion generated by the nominal rigidities is taken into account, the central bank in area $H$ faces a trade-off between stabilizing domestic inflation, output gaps and the terms-oftrade gap. These gaps embed the incentives of the policy maker of the monetary union discussed above: on the one hand the need to use the world resources efficiently; on the other hand the desire to manipulate the terms of trade between areas at the steady state and over the business cycle. Indeed, consistently with the discussion above and with Benigno and Benigno (2006), price stability is a Nash-equilibrium policy under regimes $A$ and $B$ if shocks are to productivity and $\eta \sigma=1$. However, in general, this is not the case, since the central bank of the monetary union balances the need to stabilize domestic inflation with the incentive of affecting the terms of trade over the cycle and of reducing the perceived steady-state distortion, by, for instance, influencing the covariances between mark-up shocks and output.

\section{Welfare evaluation}

There is a crucial question that is still left unanswered. What is the appropriate domain of a monetary union from the perspective of area $H$ (and $F$ ) households? Are the consumers of areas $H$ and $F$ better off under regimes $A, B$ or $C$ ? The solution to the optimal policy problems enable us to evaluate welfare under regimes $A, B$ and $C$ and to address these questions. Before examining the results on welfare, we discuss the baseline parameterization. 


\subsection{Parameterization}

The baseline parameterization of the model shown in Table 4 is chosen with the eurozone as a benchmark. The discount factor is set to 0.99 in order to match a steadystate annual interest rate of 4 percent. The intertemporal elasticity of substitution is set equal to $\frac{1}{2}$, as in Pappa (2004) and Corsetti et al. (2010), while the labor supply elasticity is $\frac{1}{3}$ and the import share over GDP of the small open region is 40 percent (i.e., $\left.\alpha_{s}=0.6\right)$ consistently with Galí and Monacelli (2005) and De Paoli (2009a). Conversely, the degree of home bias of the area is set equal to 0.85 in line with Coenen, Lombardo, Smets and Straub (2010) and Pappa (2004). The elasticities of substitution across labor types and across varieties produced within the same region are set equal to 6 and correspond to a 20 percent steady-state mark-up in the goods and in the labor markets respectively. Furthermore, we assume that governments do not subsidize labor, i.e., $\tau=0$. As a result, $\tilde{\tau}$ is equal to -0.44 and the steady-state wedge between the marginal rates of substitution and transformation is equal to 1.44, close to 1.38, the calibration chosen by Benigno and Benigno (2006). In addition, $\theta$, the probability of resetting the price, is 0.75 , implying an average price duration of one year. Moreover, we parameterize the autocorrelation and the standard deviation of productivity shocks, $\hat{a}_{t}$ as in Coenen et al. (2010). Following De Paoli (2009a) and Benigno and Benigno (2006) and in line with the findings of Adolfson, Laséesen, Lindé and Villani (2007) we assume $A R(1)$ mark-up shocks, $\hat{\mu}_{t}$, with an autocorrelation coefficient, $\rho_{\mu}$, equal to 0.9 . We set then the standard deviation of mark-up shocks consistently with Coenen et al. (2010). Finally, the correlation of productivity shocks across regions is set according to Galí and Monacelli (2005), while the correlation of mark-up shocks across regions is half that of productivity ${ }^{33}$ A more detailed description of the shock parameterization is provided in the online appendix.

There is no clear consensus in the literature on the parameterization of the trade elasticity. If we just focus on the more recent studies, Broda and Weinstein (2006) and Imbs and Méjean (2011), for instance, suggest that a reasonable parameterization of the trade elasticity should lie within 4 and 6 and above 6 respectively. Conversely using Bayesian techniques, Rabanal and Tuesta (2010) estimate this elasticity to lie below 1, consistently with the results of Corsetti, Dedola and Leduc (2008a). Then, in line with De Paoli (2009b) and Rabitsch (2012) we allow the trade elasticity to vary from 0 to $3 . .^{34}$ and within this range we study the welfare gains across the different regimes.

\subsection{Welfare gains of a monetary union}

The analysis of the previous sections reveals that in our setting there are potential welfare benefits from the adoption of a common currency. Moreover, it makes clear what the sources of these benefits are: a more efficient use of the resources available in the economy, the internalization of the spill-over effects generated within area $H$ and the gains from controlling the terms of trade across areas. Nevertheless, these benefits could be offset by the cost of being in a monetary union generated by the inability of the central bank to properly stabilize country specific shocks. We use then the household welfare based criterion derived in $(19)$ and its equivalent for area $H$ to quantify the

\footnotetext{
${ }^{33}$ Notice that this choice corresponds to a conservative configuration of this parameter. We check the sensitivity of our results to a change in $\varsigma_{s, b}$ in Forlati $(2012)$.

${ }^{34}$ This range ensures that under the baseline calibration second-order conditions for the optimal policy problems are satisfied in all regimes and purely random policies cannot be welfare improving. For a discussion on this issue, see Benigno and Benigno (2006) and Benigno and Woodford (2005).
} 
net gains from being in a currency union expressed as a fraction of the corresponding steady-state consumption. Figure 2 shows the differences in welfare under the baseline calibration between being under regimes $A$ or $B$ (first two plots), $B$ or $C$ (third plot) and $A$ or $C$ (fourth plot) for both domestic and foreign households as a function of the trade elasticity $\eta$. A change in such elasticity implies a change in the desired levels of per period output and in the corresponding perceptions of the steady-state distortion.

Three noteworthy conclusions can be drawn from this figure:

1 As the first plot suggests, if there is a group of small open economies that decide to be in a monetary union, welfare gains can be large. When $\eta$ is greater than 1.8 , the net benefits for the domestic households are positive and can reach the considerable size of 27.8 percent of steady-state consumption as $\eta$ approaches the value of 3.935 At the same time, there can be welfare losses if $\eta$ is sufficiently small. However, these losses are on average lower than the potential gains especially if we exclude the smallest values of $\eta$, which are not very plausible. The interpretation of this finding is quite clear. For high enough values of $\eta$ the costs of a monetary union due to the impossibility of properly stabilizing region-specific shocks are offset by the benefits associated with the internalization of the negative externalities produced by the small open economies.

In fact, as $\eta$ increases and domestic and foreign goods become better substitutes in the utility, the perceived steady state distortion and the incentive of the small country policy makers to improve per period terms of trade become stronger and stronger 36 Hence their monetary policy exacerbates substantially the ensued negative externalities both within and across areas. This is so since their economies being small, the regional central banks take as given what happens in the world economy. Thus, they disregard (as opposed to the monetary authority of a currency area) how their joint policy decisions affect the efficient allocation of resources of the world economy and the average performances of both areas $H$ and $F$.

2 According to the third plot of Figure 2, under the baseline calibration there are no welfare gains from being in a monetary union between the two areas. In this case welfare losses fall in the range of -0.0096 and -0.0012 of the steady-state consumption. Intuitively, if in this case the costs of being in a currency area are smaller, benefits are smaller, too, because the monetary authorities of the big economies are more concerned about inflation stabilization and less prone to adopting policies that generate negative externalities on the other area. In fact, monetary authorities of a currency area take into account how their decisions affect not only the domestic but also the foreign economy performance. They realize the importance of an efficient allocation of resources of the world economy as a whole, whereas small open economy policy makers do not.

3 According to the fourth plot, if $\eta$ is large enough, households of area $F$, and even those in area $H$, benefit substantially from being in a monetary union with the small open economies of area $H$. Again, the rationale of this result is explained by the fact that joining the monetary union can discipline the behavior of the small

\footnotetext{
${ }^{35}$ We have not plotted the values of the welfare gains for $\eta$ equal to 3.9 because altering its scale renders the figure unreadable. Similar sizes of welfare gains are found in the robustness checks provided by Forlati (2012).

${ }^{30} \mathrm{As}$ our analysis on the welfare relevant targets suggests, this incentive translates into potentially more expansionary - and then more inflationary - monetary policy. This conclusion can be even inferred by the impact responses to a global mark-up shock reported in Forlati (2012).
} 
Welfare gains from being under regime $B$ instead of $A$ for the households of area $\mathrm{H}$

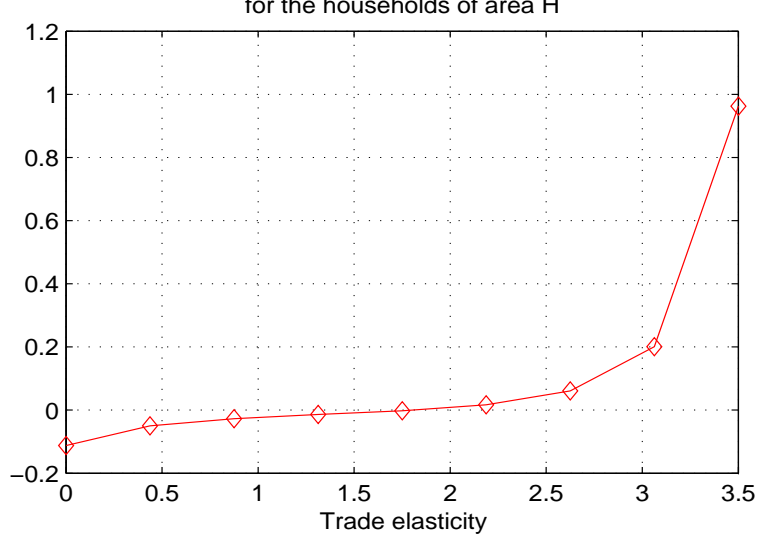

Welfare gains from being under regime $C$ instead of $B$

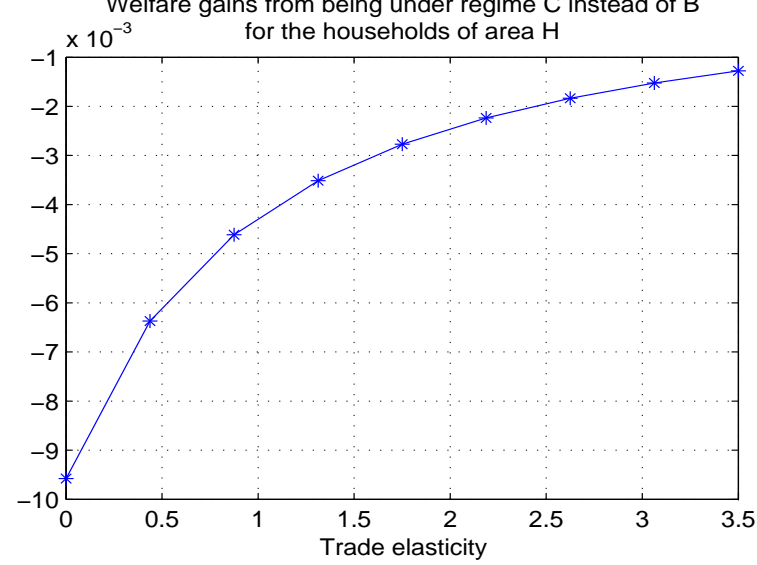

Welfare gains from being under regime $B$ instead of $A$ for the households of area $F$

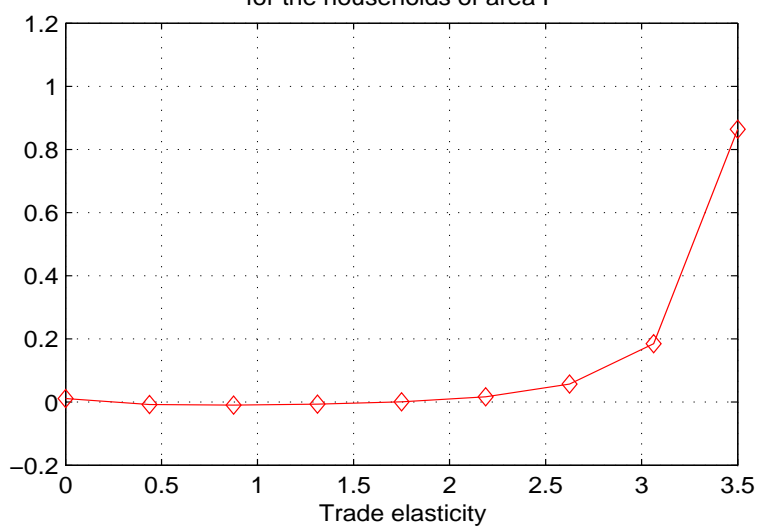

Welfare gains from being under regime $C$ instead of $A$ for the households of areas $\mathrm{H}$ and $\mathrm{F}$

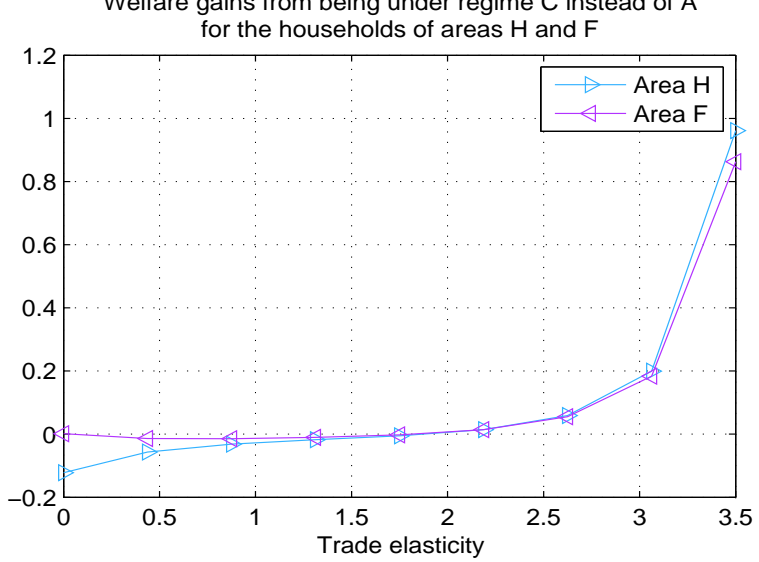

Figure 2: Welfare gains of a monetary union.

open economy policy makers. Put differently, as evident from the second plot small country policies are welfare detrimental even for the foreign area. Therefore, according to this result there is a rationale for the households of area $F$ to be in a monetary union that includes the small open countries.

We can now use the previous findings to characterize the appropriate domain of a currency area such as the European monetary union. According to our results, for sufficiently large values of $\eta$, there are welfare gains from the adoption of a currency like the euro for consumers living in an area like the eurozone. From the perspective of these consumers, it might be a good idea to try to foster the process of enlargement of the euro to other European countries. Conversely, it seems that being in a monetary union with a big country like the U.S. cannot bring about sizable welfare benefits for domestic and foreign households. In Forlati $(2012)$ we check the sensitivity of our findings to a change in several parameters: $\sigma^{-1}$, the intertemporal elasticity of substitution; $\alpha_{b}$, the degree of home bias, $\varsigma_{s, \mu}$ and $\varsigma_{b, \mu}$, the correlations of mark-up shocks across regions and areas, $\tau$, the employment subsidy, $\rho_{\mu}$, the autocorrelation of mark-up shocks and $\sigma_{\mu}$, the standard deviation of mark-up shocks. The results are quite robust to these changes.

\section{Possible Extensions}

In our framework, under coordination the optimal policy consists of the same monetary policy prescriptions followed in a closed economy. In this case, what Blanchard and 
Galí (2007) called divine coincidence holds. Under efficient shocks - as in a closed economy - it is optimal to completely stabilize firms' marginal costs so as to eliminate the cost of inflation and at the same time to reach efficient business cycle fluctuations. In this context, the fluctuations in the real exchange rate reflect the movements in the relative prices of exports versus imports and favor the efficient allocation of resources, consistently with the classical view described in Friedman (1953). As emphasized by Corsetti et al. (2010), the classical view hinges on three assumptions: that financial markets are complete ensuring perfect risk sharing; that there is perfect exchange rate pass-through and that domestic policy makers do not engage any strategic manipulation of their terms of trade. In this paper, we analyzed extensively the consequences of relaxing the third assumption for optimal monetary policies and the gains of forming a monetary union. We show that the attempt to manipulate the terms of trade renders small open economies more prone to adopt inflationary policies which can imply non-negligible welfare losses for the economy as a whole. However, we follow part of the literatur ${ }^{37}$ by assuming complete financial markets and the law of one price. In this section, we discuss to what extent these two assumptions can be critical for our results, providing new possible directions for future research.

Imperfect Pass-Through. There is a vast body of empirical studies suggesting that the exchange rate pass-through is incomplete. For instance, according to Campa and Goldberg (2005) the exchange rate pass-through in the OECD countries is 0.46 in the short run and 0.64 in the long run, far, then, from the unitary pass-through implied by the assumption of Producer-Currency Pricing (PCP). In order to reconcile this empirical evidence with the model predictions, a strand of the open macro literature ${ }^{38}$ has introduced the assumption of pricing to market i.e., the assumption that the prices of the foreign goods consumed domestically are set in the home currency - the so called Local-Currency Pricing (LCP). Under this assumption, the same good is sold at different prices at home and abroad and the fluctuations in the nominal exchange rate are not transmitted to import prices, generating an inefficient misalignment in the prices of imports and exports. For this reason, assuming LCP breaks down the divine coincidence. Indeed, under LCP in response to asymmetric productivity shocks, inflation in the domestic and export destination markets cannot be jointly stabilized, since export prices are set in foreign currency and therefore cannot fully adjust to nominal exchange rate movements ${ }^{39}$ As a result, even under technological shocks the cooperative policy maker faces a trade-off between stabilizing consumer price inflation, which includes import price inflation, international relative price misalignments and the output gap 40 Given these findings, we can expect that assuming LCP in our framework would introduce the same additional distortion, i.e., the relative price misalignment, which will change the transmission mechanism of monetary policies across regions and the incentives of open economy policy makers over the business cycle. However, even if allowing for LCP is potentially an interesting extension of our analysis, there are at least two reasons why the previous considerations should not raise major concerns for our results. On the one hand, we can reasonably presume that the mechanism explaining our main findings on the gains of being in a monetary union will be at work even under LCP.

\footnotetext{
${ }^{37}$ E.g., Clarida, Galí and Gertler (2002), Benigno and Benigno (2003), Pappa (2004), Galí and Monacelli (2005), Benigno and Benigno (2006), Galí and Monacelli (2009) and De Paoli (2009a).

${ }^{38}$ See, for instance, Devereux and Engel (2003), Corsetti and Pesenti (2005), Corsetti et al. (2010), Corsetti et al. (2011) and Engel (2011).

${ }^{39}$ In fact, most prices of domestic exports (those of non-reoptimizing firms) do not change under LCP, weakening the expenditure switching effect.

${ }^{40} \mathrm{On}$ this result see Corsetti et al. (2010) and Engel (2011).
} 
Indeed, since the assumption of LCP introduces only an additional source of nominal rigidities, we can easily conjecture that the allocation at the zero-inflation steady state and the steady-state distortions as depicted in Figure 1 remain the same. As emphasized above, the difference in the perception of the steady-state distortion is what mainly drives monetary policy makers' optimal decisions and thus the welfare benefits under the different regimes. On the other hand, as made clear by Obstfeld and Rogoff (2000) and Corsetti, Dedola and Leduc (2008b), while assuming LCP renders the exchange rate pass-through incomplete, it also implies a model prediction at odds with the empirical evidence. Indeed, for levels of price stickiness consistent with the most recent estimates provided, for instance, by Gopinath and Rigobon (2008), Nakamura and Steinsson (2008) and Midrigan (2011), a depreciation of the nominal exchange rate tends to translate into an improvement rather than into a worsening of the domestic terms of trade as shown by the results of Corsetti et al. (2010) ${ }^{41}$ Put differently, the debate on how to square the empirical evidence on the imperfect pass-through and on the correlation between the exchange rates and the terms of trade with the predictions of open macro models is still open. In this respect, the contribution of Corsetti et al. (2008b) points out, for example, how pricing to market is not the only factor that can explain the deviations from the law of one price. Real factors that generate endogenous fluctuations in the mark-up of imported goods, like the introduction of a sector of non-tradable services through which traded goods are distributed to consumers, can also help, bringing at the same time the predicted correlation between the exchange rates and the terms of trade closer to the data. One of the next challenges of the open macro literature should be to build a tractable open economy workhorse model that fits the evidence on the incomplete pass-through, on the correlation between the exchange rate and the terms of trade and on the nominal rigidities. Such a framework would allow us to identify more clearly the transmission mechanism of monetary policy across countries and to study the optimal monetary policy design under cooperation and non-cooperation jointly with the welfare gains of a monetary union.

Incomplete Financial Markets. As emphasized by Corsetti et al. (2010), once we allow for incomplete risk sharing - specifically, when there is either financial autarky or areas and/or regions trade only a nominal bond - the flexible price allocation is not efficient. The impossibility of perfectly smoothing consumption across states or times due to the lack of trade in financial assets causes what Corsetti et al. (2010) call cross-country demands imbalance and currency misalignments. For instance, under financial autarky, provided that $\eta$ is large enough, a positive productivity shock implies an excessive increase in domestic demand relative to the level reached under complete markets, which brings about an overvaluation of the real exchange rate. Intuitively, since there is no way to transfer output to future periods, the rise in current output enhanced by the technological improvement results in an increase in current consumption above efficiency. The main implication of the lack of perfect risk sharing for optimal monetary policy under cooperation is then clear: depending on the parameterization under incomplete markets, cooperative monetary policy makers have to use monetary policy to dampen or amplify the effects of macroeconomic shocks on

\footnotetext{
${ }^{41}$ As explained by Corsetti et al. (2010), under LCP and Calvo pricing, the exchange rate pass-through for the firms that cannot reoptimize is zero. Then, in response to a depreciation of the nominal exchange rate, the domestic terms of trade can improve because ceteris paribus the prices of the exported goods produced domestically by the non-reoptimizing firms increase. At the same time, the exchange rate pass-through for the firms that readjust their prices is positive with the consequence that the prices of the imported goods produced by foreign reoptimizing firms increase and generate a pressure for a terms-of-trade worsening. Which effect prevails in equilibrium is determined by the degree of price stickiness.
} 
consumption and output in order to correct for cross-country demand imbalances and exchange rate misalignments. Interestingly, it turns out that under non-cooperation assuming incomplete markets not only introduces an additional policy trade-off over the business cycle, but even changes the way in which open economy policy makers attempt to manipulate the terms of trade in their favor at the steady state.

Why this is the case can be grasped from Figure 3 , the equivalent of Figure 1 under incomplete markets. Figure 3 shows the desired levels of steady-state output for small open economy and big economy policy makers as a function of the trade elasticity $\eta$. In fact, it can be shown that, similarly to what happens under complete markets, the desired levels of steady-state output of both the small and the big open economies under financial autarky can be written as ${ }^{42}$

$$
Y_{s}^{i}=\delta_{s}^{i-\frac{1}{\sigma+\varphi}} \quad Y_{b}^{i}=\left(1-\frac{\left(1-\delta_{b}^{i}\right)(\sigma+\varphi)}{(\sigma-1)+(\varphi+1) \delta_{b}^{i}}\right)^{-\frac{1}{\sigma+\varphi}}
$$

where $i$ stands for incomplete markets and $\delta_{s}^{i} \equiv \frac{\eta\left(1+\alpha_{s}\right)-\alpha_{s}}{\eta\left(1+\alpha_{s}\right)-1}$ and $\delta_{b}^{i} \equiv \frac{2 \alpha_{b}(\eta-1)}{2 \alpha_{b} \eta-1}$ are the parameters governing the elasticity of consumption to output in the small and big economies, respectively.

Figure 3 exhibits a common feature with Figure 1; small open economy authorities tend to produce stronger negative spillovers than those of large countries. However, there are at least two striking differences between Figures 1 and 3 . Under complete markets, the higher the $\eta$, the lower are the desired levels of output. Moreover, the levels of steady-state output are monotonic functions of $\eta$. Differently, under incomplete markets, the desired levels of steady-state output are not monotonically increasing in $\eta$. For high enough values of $\eta 43$ open economy policy makers have an incentive to undersubsidize labor with respect to what is efficient in order to improve their terms of trade. In this way, since in equilibrium there is balanced trade, they can import more for each unit of exports. Production falls and consumption falls too but not as much as production, so as to improve domestic welfare. The stronger the incentive to improve the terms of trade, the lower the trade elasticity. In fact, the lower the trade elasticity, the lower the impact of the terms-of-trade amelioration on foreign demand for domestically produced goods and the larger the increase in domestic imports for each unit of exports.

Conversely, when the trade elasticity is low, the behavior of uncoordinated authorities is more puzzling and can be understood recalling the uninsurable effects on wealth, highlighted by the seminal contribution of Corsetti et al. (2008a that characterize open economy models under incomplete markets. Indeed, according to Corsetti et al. (2008a) provided that $\eta$ is sufficiently low, an improvement of the terms of trade entails an expansion in the domestic demand of home produced goods, since as the terms of trade improve, the value of domestic production increases relative to foreign production, generating a positive wealth effect that more than offsets the substitution effect associated with the terms-of-trade improvement. If this wealth effect is strong enough, open economy policy makers find it optimal to oversubsidize labor with respect to what is efficient under cooperation. Raising the labor subsidy beyond efficiency generates a

\footnotetext{
${ }^{42}$ See the online appendix. Notice that under incomplete financial markets the desired level of steady state output under cooperation coincides with the Pareto efficient level.

${ }^{43}$ Specifically, when $\delta_{s}^{i}>1$ in the case of the small open economy and when $\delta_{b}^{i}>1$ and at the same time $\sigma-1+(\varphi+1) \delta_{h}^{i}>0$ in the case of the large economy.

${ }^{44}$ Corsetti et al. (2008a) show how imperfect risk sharing combined with low trade elasticities helps to reconcile international business cycle models with the "Backus Smith" puzzle - i.e., the empirical evidence that there is a low and negative correlation between the real exchange rate and the relative consumption.
} 


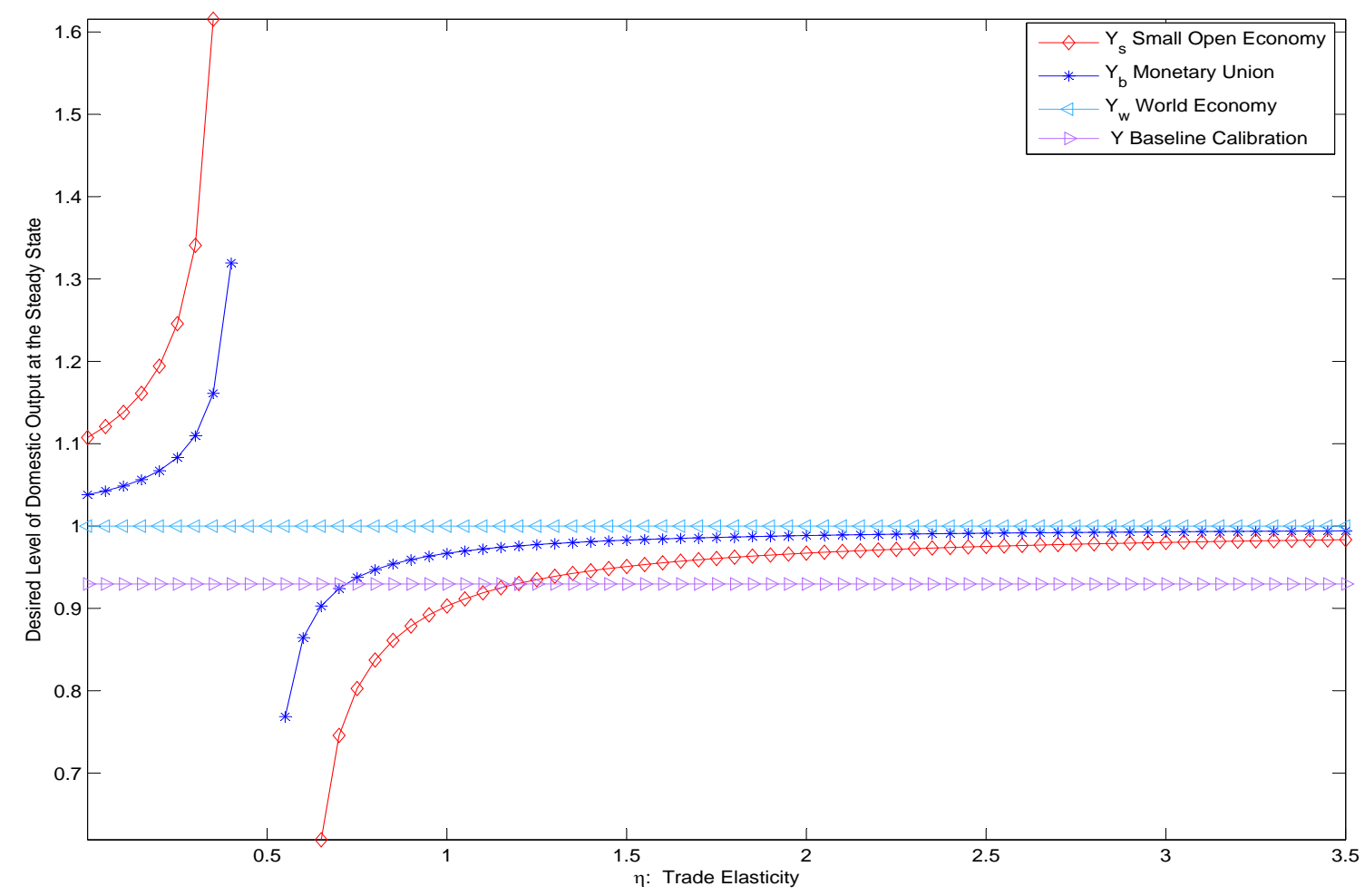

Figure 3: Desired level of steady state domestic output as a function of the trade elasticity $\eta$ under financial autarky.

downward pressure on prices of domestically produced goods and an upward pressure on the real wage. The positive income effect associated with the latter pushes the home demand for domestic goods upward, more than compensating for the downward pressure on home prices. As a result, the domestic terms of trade improve and the value of domestic production increases, allowing for a strong wealth effect that reinforces the increase in domestic demand for home goods. Output increases but consumption increases by more so as to improve welfare. Notice that in this case the stronger the incentive of increasing the labor subsidy, the higher the trade elasticity, since the higher this elasticity the larger the increase in domestic demand for home goods and the stronger the positive wealth effect.

The above discussion clarifies how relaxing the assumption of complete financial markets is a potentially interesting extension of our model. In fact, once this assumption is relaxed, the set of parametric configurations under which there are gains from being in a monetary union presumably changes. However, we can expect that the main conclusion of our analysis survives even in the absence of complete risk sharing. Indeed, even under these circumstances the incentive to generate negative externalities - and then the case for a monetary union - is stronger for the authorities of a group of small open economies, since these authorities disregard the joint effects of their policies on foreign economies. For this reason, the assumption of complete financial markets should not be considered too restrictive. At the same time, given the multi-country set up we used and the purposes of our paper, focused mainly on the Euro Area which, 
in the recent decades, has been undergoing through a rapid process of financial integration, assuming that there is either financial autarky or trade only in one bond could be considered extreme too. In fact, the literature has only partially explored the consequences of different financial market structure arrangements for the optimal design of monetary policy, focusing mainly on three cases: complete financial markets, bond economies and financial autarky ${ }^{45}$ A possible interesting direction for future research could be to extend the analysis even to the cases in which there is trade in multiple assets, but financial markets are incomplete. In this way, it would be possible to compare the transmission mechanism of monetary policy, the incentives of monetary policy makers and the welfare gains of monetary union under a larger range of financial market arrangements. This type of analysis would, however, be quite complex, even because it requires us to determine the optimal portfolio dynamics endogenously as made clear by Devereux and Sutherland (2010).

Other Extensions. Beyond the extensions mentioned above which are strictly related with the most recent research progresses of the open macro literature, there are at least two other extensions that could be worth investigating. In our framework, we assume that there are two areas of equal size and we take the size of the area forming a monetary union as given. In the spirit of the literature on the optimum currency area, it could be interesting to study the welfare gains of a monetary union by assuming multiple areas or allowing for the size of the areas to be different. Being even more ambitious, one could aim at finding the optimal number of currencies within a New Keynesian multi-country and multi-area set up 46 Another possible extension could investigate whether the introduction of a sovereign-debt market and sovereign-debt spreads could undermine the welfare gains of a monetary union due to the elimination of beggar-thy-neighbor policies. Notice how this type of extension could help to clarify, for instance, whether a monetary union requires fiscal policy coordination to be beneficial for its citizens.

\section{Conclusion}

This paper provides a possible rationale for the process of the creation and enlargement of the eurozone. It shows that, as long as the monetary union is formed by a group of small open economies, there can be sizable welfare gains from sharing the same currency and from extending the currency area to another group of small open economies. Our findings stem from the incentive of small open countries to generate potentially strong negative externalities, which lead to large inflation volatility both in the foreign area, which has a single monetary authority, and in the domestic area, in which the small open countries still retain monetary autonomy. In this case, delegating the monetary policy to a common central bank that sets the interest rate for the whole area acts as a disciplining device against the beggar-thy-neighbor policies of the small open economies.

\footnotetext{
${ }^{45}$ On this issue see, for instance, De Paoli (2009b), Corsetti et al. (2010) and Corsetti et al. (2011).

${ }^{46}$ Note that within this type of analysis it could be worth even to relax the assumption of equal elasticity for trade between countries within the same area and between areas since in this way it would be possible to disentangle the terms-of-trade effects across areas from those across countries.
} 


\section{References}

Adolfson, Malin, Stefan Laséesen, Jesper Lindé and Mattias Villani, "Bayesian Estimation of an Open Economy DSGE Model with Incomplete Passthrough," Journal of International Economics, 2007, 72 (2), 481-511.

Alesina, Alberto and Robert J. Barro, "Currency Unions," Quarterly Journal of Economics, 2002, 17 (2), 409-36.

Bagwell, Kyle and Robert W. Staiger, "An Economic Theory of GATT," American Economic Review, 1999, 89 (1), 215-48.

_ and _, "What Do Trade Negotiators Negotiate About? Empirical Evidence from the World Trade Organization," American Economic Review, 2011, 101 (4), 1238 1273 .

Benigno, Gianluca and Pierpaolo Benigno, "Price Stability in Open Economies," Review of Economic Studies, 2003, 70 (4), 743-64.

_ and _ , "Designing Targeting Rules for International Monetary Policy Cooperation," Journal of Monetary Economics, 2006, 53 (3), 473-506.

_ and _ , "Implementing International Monetary Cooperation through Inflation Targeting," Macroeconomic Dynamics, 2008, 12 (1), 45-59.

Benigno, Pierpaolo and Michael Woodford, "Inflation Stabilization and Welfare: The Case of a Distorted Steady State," Journal of the European Economics Association, 2005, 3 (6), 1185-236.

_ and _ , "Linear-quadratic Approximation of Optimal Policy Problems," Journal of Economic Theory, 2012, 147 (1), 1-42.

Blanchard, Oliver and Jordi Galí, "Real Wage Rigidities and New Keynesian Model," Journal of Money, Credit and Banking, 2007, 39 (1), 35-65.

Broda, Christian and David E. Weinstein, "Globalization and the Gains from Variety," Quarterly Journal of Economics, 2006, 121 (2), 541-85.

Broda, Christian, Nuno Limão and David E. Weinstein, "Optimal Tariffs and Market Power: The Evidence," American Economic Review, 2008, 98 (5), 2032-65.

Campa, José Manuel and Linda Goldberg, "Exchange Rate Pass-Through into Import Prices," Review of Economics and Statistics, 2005, 87 (4), 679-690.

Clarida, Richard, Jordi Galí, and Mark Gertler, "A Simple Framework for International Monetary Policy Analysis," Journal of Monetary Economics, 2002, 49 (5), 879-904.

Coenen, Günter, Giovanni Lombardo, Frank Smets, and Roland Straub, "International Transmission and Monetary Policy Cooperation," in Jordi Galí and Mark J. Gertler, eds., International Dimensions of Monetary Policy,Chicago IL: University of Chicago Press, 2010.

Corsetti, Giancarlo and Paolo Pesenti, "Welfare and Macroeconomic Interdependence," Quarterly Journal of Economics, 2001, 16 (2), 421-46. 
_ and _ , "International Dimensions of Optimal Monetary Policy," Journal of Monetary Economics, 2005, 52 (2), 282-305.

_ , Luca Dedola, and Sylvan Leduc, "International Risk Sharing and the Transmission of Productivity Shocks," Review of Economic Studies, 2008a, 75 (2), 443-473.

_ , _ , and _ , "High Exchange Rate Volatility and Low Pass-Through," Journal of Monetary Economics, 2008b, 55 (6), 1113-1128.

_ , _ , and _ , "Optimal Monetary Policy in Open Economies," in Ben Friedman and Michael Woodford, eds., The Handbook of Monetary Economics, Vol. III, Amsterdam, HOL: Elsevier, 2010.

_ , _ , and _ , "Demand Imbalances, Exchange-Rate Misalignments and Monetary Policy" Mimeo, 2011.

De Paoli, Bianca, "Monetary Policy and Welfare in a Small Open Economy," Journal of International Economics, 2009, 77 (1), 11-22.

_ , "Monetary Policy in a Small Open Economy: the Role of the Asset Market Structure," Journal of Money, Credit and Banking, 2009, 41 (7), 1301-1330.

Devereux, Michael B. and Charles Engel, "Monetary Policy in the Open Economy Revisited: Price-Setting and Exchange-Rate Flexibility," Review of Economic Studies, 2003, 70 (4), 765-783.

Devereux, Michael B. and Alan Sutherland, "Country Portfolio Dynamics," Journal of Economic Dynamics and Control, 2010, 34 (7), 1325-1342.

Engel, Charles, "Currency Misalignments and Optimal Monetary Policy: A Reexamination" American Economic Review, 2011, 101 (6), 2796-2822.

Epifani, Paolo and Gino Gancia, "Openness, Government Size and the Terms of Trade," Review of Economic Studies, 2009, 76 (2), 629-68.

Forlati, Chiara, " On the Benefits of Monetary Union: Does it Pay to be Bigger?" Mimeo, 2012.

Friedman, Milton, "The Case for Flexible Exchange Rates" in Essays in Positive Economics, Chicago, IL: University of Chicago Press, 1953.

Galí, Jordi, Monetary Policy, Inflation, and the Business Cycle, Princeton, NJ: Princeton University Press, 2008.

- and Tommaso Monacelli, "Monetary Policy and Exchange Rate Volatility in a Small Open Economy," Review of Economic Studies, 2005, 72 (3), 707-734.

_ and _ , "Optimal Monetary and Fiscal Policy in a Currency Union," Journal of International Economics, 2009, 76 (1), 116-132.

Gopinath, Gita and Roberto Rigobon, "Sticky Borders," Quarterly Journal of Economics, 2008, 123 (2), 531-575.

Grossman, Gene M. and Elhanan Helpman, "Trade Wars and Trade Talks," Journal of Political Economy, 1995, 103(4), 675-708. 
Imbs, Jean and Isabelle Méjean, "Elasticity Optimism," American Economic Journal: Macroeconomics 2015, 7(3), 43-83.

Johnson, Harry G., "Optimum Tariffs and Retaliation," Review of Economic Studies, 1953, 21 (1), 142-143.

Lucas, Robert E. Jr., Models of Business Cycles, Oxford, UK: Basil Blackwell, 1987.

_ , "Macroeconomic Priorities," American Economic Review, 2003, 93 (1), 1-14.

Midrigan, Virgiliu, "Menu Cost, Multiproduct Firms, and Aggregate Fluctuations," Econometrica, 2011, 79 (4), 1139-1180.

Mundell, Robert A., "A Theory of Optimum Currency Areas," American Economic Review, 1961, 51 (4), 657-75.

Nakamura, Emi and Jón Steinsson, "Five Facts About Prices: A Reevaluation of Menu Cost Models," Journal of Quarterly Economics , 2008, 123(4), 1415-1464.

Obstfeld, Maurice and Kenneth Rogoff, "New Directions for Stochastic Open Economy Models," Journal of International Economics, 2000, 50 (1), 117-154.

Obstfeld, Maurice and Kenneth Rogoff, "Global Implications of Self-Oriented National Monetary Policy Rules," Quarterly Journal of Economics, 2002, 117 (2), 503-536.

Pappa, Evi, "Do the ECB and the Fed Really Need to Cooperate? Optimal Monetary Policy in a Two-Country World," Journal of Monetary Economics, 2004, 51 (4), 753-779.

Rabanal, Pau and Vincente Tuesta, "Euro-Dollar Real Exchange Rate Dynamics in an Estimated Two-Country Model: An Assessment," Journal of Economic Dynamics and Control, 2010, 34 (4), 780-97.

Rabitsch, Katrin, "The Role of Financial Market Structure and the Trade Elasticity for Monetary Policy in Open Economies,", Journal of Money, Credit and Banking, 2012, 44 (4), 603-629.

Rose, Andrew K. and Eric van Wincoop, "National Money as a Barrier to International Trade: The Real Case for Currency Union," American Economic Review, 2001, 91 (2), 386-390.

Rotemberg, Julio J. and Michael Woodford, "An Optimization-Based Econometric Framework for the Evaluation of Monetary Policy," NBER Macroeconomic Annual, 1997.

Silva Santos, Jão M.C. and Silvana Tenreyro, "Currency Unions in Prospect and Retrospect," Annual Economic Review, 2010, 2, 51-74.

Tille, Cedric, "The Role of Consumption Substitutability in the International Transmission of Shocks," Journal of International Economics, 2001, 53 (2), 421-444.

Woodford, Michael, Interest and Prices: Foundations of a Theory of Monetary Policy, Princeton, NJ: Princeton University Press, 2003. 


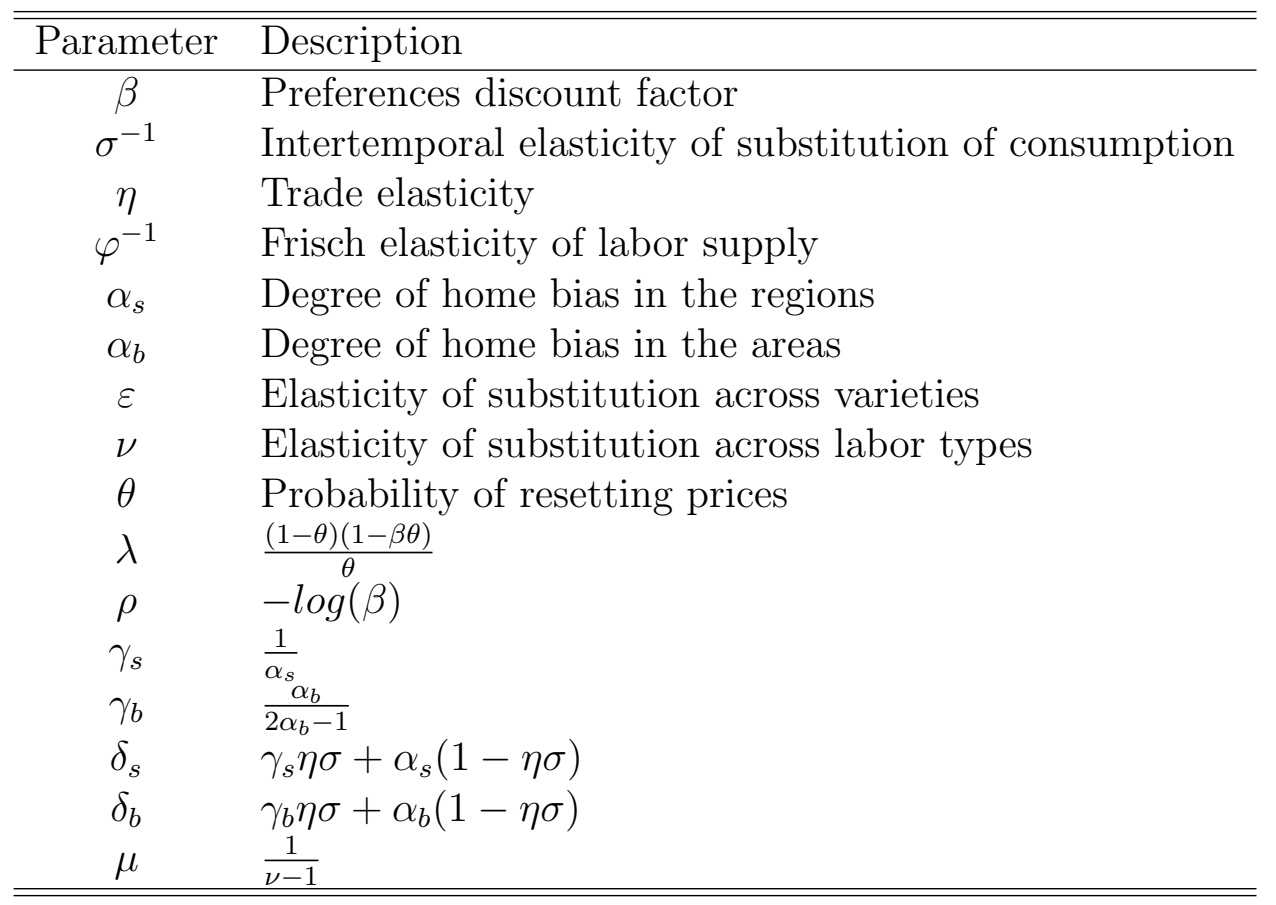

Table 3: Model Parameters.

\begin{tabular}{crl}
\hline \hline Parameter & Value & Description \\
\hline$\beta$ & 0.99 & Preferences discount factor \\
$\sigma^{-1}$ & $1 / 2$ & Intertemporal elasticity of substitution of consumption \\
$\varphi^{-1}$ & $1 / 3$ & Frisch elasticity of labor supply \\
$\alpha_{s}$ & 0.6 & Degree of home bias in the regions \\
$\alpha_{b}$ & 0.85 & Degree of home bias in the areas \\
$\varepsilon$ & 6 & Elasticity of substitution across varieties \\
$\nu$ & 6 & Elasticity of substitution across labor types \\
$\theta$ & 0.75 & Probability of resetting prices \\
$\rho_{a}$ & 0.9 & Autocorrelation of technological shocks \\
$\rho_{\mu}$ & 0.9 & Autocorrelation of mark-up shocks \\
$\tau$ & 0 & Steady-state labor subsidy \\
$\sigma_{a}$ & 0.0055 & Standard deviation of technological shocks \\
$\sigma_{\mu}$ & 0.0262 & Standard deviation of mark-up shocks \\
$\varsigma_{a, b}$ & 0.258 & Correlation of productivity shocks across areas \\
$\varsigma_{a, s}$ & 0.3 & Correlation of productivity shocks across regions \\
$\varsigma_{\mu, b}$ & 0.129 & Correlation of mark-up shocks across areas \\
$\varsigma_{\mu, s}$ & 0.15 & Correlation of mark-up shocks across regions \\
\hline \hline
\end{tabular}

Table 4: Baseline Parameterization. 


\section{Appendix}

\section{A The Model}

\section{A.1 Preferences}

Agents are infinitely lived and maximize the expected value of the discounted sum of the per-period utility. Preferences of a generic household $s$ of region $i$ are defined over a private consumption bundle, $C_{t}^{i}$, and a labor service $s^{i}, N_{t}\left(s^{i}\right)$ :

$$
E_{0} \sum_{t=0}^{\infty} \beta^{t}\left[\frac{C_{t}^{i 1-\sigma}}{1-\sigma}-\frac{N_{t}\left(s^{i}\right)^{\varphi+1}}{\varphi+1}\right] \quad 0<\beta<1
$$

where $\beta$ is the intertemporal preferences discount factor. Agents consume all the goods produced in the world economy, but preferences exhibit home bias. The private consumption index is a CES aggregation of the following type:

$$
C_{t}^{i} \equiv\left[\alpha_{s}^{\frac{1}{\eta}} C_{i, t}^{i \frac{\eta-1}{\eta}}+\left(\alpha_{b}-\alpha_{s}\right)^{\frac{1}{\eta}} C_{H, t}^{i \frac{\eta-1}{\eta}}+\left(1-\alpha_{b}\right)^{\frac{1}{\eta}} C_{F, t}^{i \frac{\eta-1}{\eta}}\right]^{\frac{\eta}{\eta-1}}
$$

for all $i \in\left[0, \frac{1}{2}\right), \eta>0,0<\alpha_{s}<\alpha_{b}$ and $\frac{1}{2}<\alpha_{b}<1$. $\alpha_{s}$ and $\alpha_{b}$ are the degrees of home bias for the goods produced within region $i$ and the area to which region $i$ belongs, respectively. At the same time the consumption bundles $C_{H, t}^{i}, C_{F, t}^{i}$ and $C_{i, t}^{i}$ are defined as:

$$
\begin{gathered}
C_{H, t}^{i} \equiv\left[2^{\frac{1}{\eta}} \int_{0}^{\frac{1}{2}} C_{j, t}^{i \frac{\eta-1}{\eta}} d j\right]^{\frac{\eta}{\eta-1}} \quad C_{F, t}^{i} \equiv\left[2^{\frac{1}{\eta}} \int_{\frac{1}{2}}^{1} C_{j, t}^{i \frac{\eta-1}{\eta}} d j\right]^{\frac{\eta}{\eta-1}} \\
C_{j, t}^{i} \equiv\left(\int_{0}^{1} c_{t}^{i}\left(h^{j}\right)^{\frac{\varepsilon-1}{\varepsilon}} d h^{j}\right)^{\frac{\varepsilon}{\varepsilon-1}} j \in\left[0, \frac{1}{2}\right) \quad C_{j, t}^{i} \equiv\left(\int_{0}^{1} c_{t}^{i}\left(f^{j}\right)^{\frac{\varepsilon-1}{\varepsilon}} d f^{j}\right)^{\frac{\varepsilon}{\varepsilon-1}} j \in\left[\frac{1}{2}, 1\right]
\end{gathered}
$$

where $\eta$ denotes the elasticity of substitution both between $C_{H, t}^{i}, C_{F, t}^{i}$ and $C_{i, t}^{i}$ and between different $C_{j, t}^{i}$ with $j \neq i$, while $\varepsilon$ represents the elasticity of substitution among goods produced in the same region. The definition of the private consumption index (32) enables us to determine a consistent definition for the consumers' price index of region $i$, given by:

$$
P_{C^{i}, t} \equiv\left[\alpha_{s} P_{i, t}^{1-\eta}+\left(\alpha_{b}-\alpha_{s}\right) P_{H, t}^{1-\eta}+\left(1-\alpha_{b}\right) P_{F, t}^{1-\eta}\right]^{\frac{1}{1-\eta}}
$$

for all $i \in\left[0, \frac{1}{2}\right)$, where all prices are denominated in the currency of the home country. The variables $P_{i, t}, P_{H, t}$ and $P_{F, t}$ are producers' price indexes that are defined consistently with the other consumption indexes (33) and (34). The law of one price is assumed to hold in all single-good markets. However, given the home bias in preferences, in general purchasing power parity does not hold for indexes $P_{C^{i}, t}$. Symmetric definitions apply to the region of area $F$.

\section{A.2 Firms, technology and price setting}

In each region $i$ there is a continuum of firms. Each of them produces a single differentiated good with a constant return to scale technology of the type:

$$
y_{t}\left(h^{i}\right)=A_{t}^{i} N_{t}\left(h^{i}\right)
$$


with $N_{t}\left(h^{i}\right)=\left[\int_{0}^{1} N_{t}\left(s^{i}, h^{i}\right)^{\frac{v_{t}^{i}-1}{v_{t}^{i}}} d s^{i}\right]^{\frac{v_{t}^{i}}{v_{t}^{i}-1}}$ being the labor input bundle, composed of a continuum of imperfectly substitutable labor services ${ }^{47}$ Moreover, $A_{t}^{i}$ is the regionspecific technology shock. Given (36) and the fact that $N_{t}\left(s^{i}, h^{i}\right)=N_{t}\left(h^{i}\right)$ for all $h^{i}$ and $s^{i}$, the aggregate relationship between output and labor can be written as:

$$
N_{t}^{i}=\frac{Y_{t}^{i}}{A_{t}^{i}} Z_{t}^{i}
$$

where $Y_{t}^{i} \equiv\left[\int_{0}^{1} y_{t}\left(h^{i}\right)^{\frac{\varepsilon-1}{\varepsilon}} d h^{i}\right]^{\frac{\varepsilon}{\varepsilon-1}}, Z_{t}^{i} \equiv \int_{0}^{1} \frac{y_{t}\left(h^{i}\right)}{Y_{t}^{i}} d h^{i}$ and $N_{t}^{i} \equiv \int_{0}^{1} N_{t}\left(h^{i}\right) d h^{i}$. Using the demand functions one can show that $Z_{t}^{i}=\int_{0}^{1}\left(\frac{p_{t}\left(h^{i}\right)}{P_{i, t}}\right)^{-\varepsilon} d h^{i}$; thus $Z_{t}^{i}$ can be interpreted as an index of the relative price dispersion or output dispersion across firms. We assume that goods prices adjust according to a staggered mechanism à la Calvo. Therefore, in each period a given firm can re-optimize its price only with probability $1-\theta$. As a result, the fraction of firms that set a new price is fixed and the aggregate producer price index of the intermediate goods evolves accordingly to:

$$
P_{i, t}^{1-\varepsilon}=\theta P_{i, t-1}^{1-\varepsilon}+(1-\theta) \tilde{p}_{t}\left(h^{i}\right)^{1-\varepsilon}
$$

with $\tilde{p}_{t}\left(h^{i}\right)$ being the optimal price. Firms maximize the discounted expected sum of the future profits that would be collected if the optimal price could not be changed, namely:

$$
\sum_{s=0}^{\infty}(\theta)^{s} E_{t}\left\{Q_{t, t+s}^{i} y_{t+s}\left(h^{i}\right)\left[\tilde{p}_{t}\left(h^{i}\right)-M C_{i, t+s}^{n}\right]\right\}
$$

where $y_{t}\left(h^{i}\right)=\left(\frac{p_{t}\left(h^{i}\right)}{P_{i, t}}\right)^{-\varepsilon} Y_{t}^{i}$ and $M C_{i, t}^{n}=\frac{\left(1-\tau^{i}\right) W_{i, t}}{A_{t}^{i}}$ is the nominal marginal cost with $\tau^{i}$ denoting a constant labor subsidy.

\section{A.3 International risk sharing}

The assumption of complete markets implies:

$$
\frac{C_{t}^{i-\sigma}}{P_{C^{i}, t}}=\frac{C_{t}^{j-\sigma}}{\mathcal{E}_{i j, t} P_{C^{j}, t}}
$$

for all $t, i \in\left[0, \frac{1}{2}\right)$ and $j \in\left[\frac{1}{2}, 1\right]$, where $\mathcal{E}_{i j, t}$ denotes the nominal exchange rate of region $j$ currency relative to region $i$ currency. By appropriately integrating this equation we obtain:

$$
\frac{C_{t}^{i-\sigma}}{P_{C^{i}, t}}=\frac{C_{H, t}^{*-\sigma}}{\mathcal{E}_{i H, t} P_{H, t}^{*}} \quad i \in\left[0, \frac{1}{2}\right) \quad \frac{C_{t}^{i-\sigma}}{P_{C^{i}, t}}=\frac{C_{F, t}^{*-\sigma}}{\mathcal{E}_{i F, t} P_{F, t}^{*}} \quad i \in\left[\frac{1}{2}, 1\right] \quad \frac{C_{H, t}^{*-\sigma}}{P_{H, t}^{*}}=\frac{C_{F, t}^{*-\sigma}}{\mathcal{E}_{H F, t} P_{F, t}^{*}}
$$

for all $i$, where $C_{H, t}^{*} \equiv\left[2 \int_{0}^{\frac{1}{2}} C_{t}^{j-\sigma(1-\eta)} d j\right]^{\frac{-1}{\sigma(1-\eta)}}$ and $P_{H, t}^{*} \equiv\left[2 \int_{0}^{\frac{1}{2}}\left(\mathcal{E}_{H j, t} P_{C^{j}, t}\right)^{(1-\eta)} d j\right]^{\frac{1}{(1-\eta)}}$. Symmetric definitions apply to $C_{F, t}^{*}$ and $P_{F, t}^{*}$.

Here $\mathcal{E}_{H i, t}$ stands for the nominal exchange rate of region $i$ currency to a common unit of account of area $H$. Note that within area $F, \mathcal{E}_{F i, t}=1$ for all $i \in\left[\frac{1}{2}, 1\right]$.

\footnotetext{
${ }^{47} \mathrm{By}$ assumption, therefore, every household works in all firms.
} 
Conversely within area $H, \mathcal{E}_{H i, t}=1$ for all $i \in\left[0, \frac{1}{2}\right)$ only under regimes $B$ and $C$. Finally, in general, $\mathcal{E}_{H F, t}$ is floating under both regimes $A$ and $B$ while it is fixed to 1 under regime $C$.

Given the definitions of $P_{H, t}^{*}$ and $P_{F, t}^{*}$ it is easy to show that:

$\mathcal{E}_{i H, t} P_{H, t}^{*}=\left[\alpha_{b} P_{H, t}^{1-\eta}+\left(1-\alpha_{b}\right) P_{F, t}^{1-\eta}\right]^{\frac{1}{1-\eta}} \quad \mathcal{E}_{i F, t} P_{F, t}^{*}=\left[\alpha_{b} P_{F, t}^{1-\eta}+\left(1-\alpha_{b}\right) P_{H, t}^{1-\eta}\right]^{\frac{1}{1-\eta}}$

By 42 ):

$\frac{\mathcal{E}_{i H, t} P_{H, t}^{*}}{P_{H, t}}=\left[\alpha_{b}+\left(1-\alpha_{b}\right)\left(\frac{P_{F, t}}{P_{H, t}}\right)^{1-\eta}\right]^{\frac{1}{1-\eta}} \quad \frac{\mathcal{E}_{i F, t} P_{F, t}^{*}}{P_{F, t}}=\left[\alpha_{b}+\left(1-\alpha_{b}\right)\left(\frac{P_{H, t}}{P_{F, t}}\right)^{1-\eta}\right]^{\frac{1}{1-\eta}}$

which jointly with (41) leads to:

$$
\left(\frac{C_{F, t}^{*}}{C_{H, t}^{*}}\right)=\left[\frac{\alpha_{b}\left(\frac{P_{F, t}}{P_{H, t}}\right)^{1-\eta}+\left(1-\alpha_{b}\right)}{\left(1-\alpha_{b}\right)\left(\frac{P_{F, t}}{P_{H, t}}\right)^{1-\eta}+\alpha_{b}}\right]^{-\frac{1}{\sigma(1-\eta)}}
$$

Moreover thanks to the fact that 48

$$
\begin{gathered}
P_{C^{i}, t} \equiv\left[\alpha_{s} P_{i, t}^{1-\eta}+\left(\alpha_{b}-\alpha_{s}\right) P_{H, t}^{1-\eta}+\left(1-\alpha_{b}\right) P_{F, t}^{1-\eta}\right]^{\frac{1}{1-\eta}} \\
\frac{P_{i, t}}{P_{C^{i}, t}}=\left[\frac{1}{\alpha_{s}}-\frac{\alpha_{b}-\alpha_{s}}{\alpha_{s}}\left(\frac{P_{H, t}}{P_{C^{i}, t}}\right)^{1-\eta}-\frac{\left(1-\alpha_{b}\right)}{\alpha_{s}}\left(\frac{P_{F, t}}{P_{C^{i}, t}}\right)^{1-\eta}\right]^{\frac{1}{1-\eta}} i \in\left[0, \frac{1}{2}\right)
\end{gathered}
$$

from which using (41) it follows that:

$\frac{P_{i, t}}{P_{C^{i}, t}}=\left[\frac{1}{\alpha_{s}}-\frac{\alpha_{b}-\alpha_{s}}{\alpha_{s}}\left(\frac{P_{H, t}}{\mathcal{E}_{i H, t} P_{H, t}^{*}} \frac{C_{H, t}^{*-\sigma}}{C_{t}^{i-\sigma}}\right)^{(1-\eta)}-\frac{\left(1-\alpha_{b}\right)}{\alpha_{s}}\left(\frac{P_{F, t}}{\mathcal{E}_{i F, t} P_{F, t}^{*}} \frac{C_{F, t}^{*-\sigma}}{C_{t}^{i-\sigma}}\right)^{(1-\eta)}\right]^{\frac{1}{1-\eta}}$

Finally, by using (43) and (44) we can rewrite 47) as:

$$
\frac{P_{i, t}}{P_{C^{i}, t}}=\left[\gamma_{s}+\left(\gamma_{b}-\gamma_{s}\right)\left(\frac{C_{H, t}^{*}}{C_{t}^{i}}\right)^{-\sigma(1-\eta)}+\left(1-\gamma_{b}\right)\left(\frac{C_{F, t}^{*}}{C_{t}^{i}}\right)^{-\sigma(1-\eta)}\right]^{\frac{1}{1-\eta}}
$$

for $i \in\left[0, \frac{1}{2}\right)$ and where $\gamma_{s} \equiv \frac{1}{\alpha_{s}}$ and $\gamma_{b} \equiv \frac{\alpha_{b}}{2 \alpha_{b}-1}$. A corresponding condition can be retrieved for area $F$.

\section{A.4 The Non-Linear Equilibrium Conditions}

Given the assumptions on preferences, technology and international risk sharing discussed in the previous sections, the market equilibrium is determined by the following

\footnotetext{
${ }^{48}$ This definition for the consumers' price index of region $i$ follows from the assumption of CES preferences as stated in Appendix B
} 
conditions:

$$
\begin{aligned}
& Y_{t}^{i}=\left(\frac{P_{i, t}}{P_{C^{i}, t}}\right)^{-\eta}\left(\alpha_{s} C_{t}^{i}+\left(\alpha_{b}-\alpha_{s}\right) C_{t}^{i \sigma \eta} \mathcal{C}_{H, t}+\left(1-\alpha_{b}\right) C_{t}^{i \sigma \eta} \mathcal{C}_{F, t}\right) \quad i \in\left[0, \frac{1}{2}\right) \\
& Y_{t}^{i}=\left(\frac{P_{i, t}}{P_{C^{i}, t}}\right)^{-\eta}\left(\alpha_{s} C_{t}^{i}+\left(\alpha_{b}-\alpha_{s}\right) C_{t}^{i \sigma \eta} \mathcal{C}_{F, t}+\left(1-\alpha_{b}\right) C_{t}^{i \sigma \eta} \mathcal{C}_{H, t}\right) \quad i \in\left[\frac{1}{2}, 1\right] \\
& K_{t}^{i}=\left(\frac{Y_{t}^{i}}{A_{t}^{i}}\right)^{\varphi+1} Z_{t}^{i \varphi}\left(1+\mu_{t}^{i}\right)\left(1-\tau^{i}\right) \frac{\varepsilon}{\varepsilon-1}+\beta \theta E_{t}\left\{\Pi_{i, t+1}^{\varepsilon} K_{t+1}^{i}\right\} \quad i \in[0,1] \\
& F_{t}^{i}=Y_{t}^{i} C_{t}^{i-\sigma} \frac{P_{i, t}}{P_{C^{i}, t}}+\beta \theta E_{t}\left\{\Pi_{i, t}^{\varepsilon-1} F_{t}^{i}\right\} \\
& i \in[0,1] \\
& F_{t}^{i}=K_{t}^{i}\left(\frac{1-\theta \Pi_{i, t}^{\varepsilon-1}}{1-\theta}\right)^{\frac{1}{\varepsilon-1}} \\
& Z_{t}^{i}=\theta Z_{t-1}^{i} \Pi_{i, t}^{\varepsilon}+(1-\theta)\left(\frac{1-\theta \Pi_{i, t}^{\varepsilon-1}}{1-\theta}\right)^{\frac{\varepsilon}{\varepsilon-1}} \\
& \frac{1}{1+r_{t}^{i}}=\beta E_{t}\left\{\left(\frac{C_{t+1}^{i}}{C_{t}^{i}}\right)^{-\sigma} \frac{P_{i, t+1}}{P_{C^{i}, t+1}} \frac{P_{C^{i}, t}}{P_{i, t}} \Pi_{i, t+1}^{-1}\right\} \\
& \frac{C_{H, t}^{*-\sigma}}{C_{H, t-1}^{*-\sigma}} \frac{P_{H, t}}{\mathcal{E}_{i H, t} P_{H, t}^{*}} \frac{\mathcal{E}_{i H, t-1} P_{H, t-1}^{*}}{P_{H, t-1}} \Pi_{H, t}^{-1}=\frac{C_{t}^{i-\sigma}}{C_{t-1}^{i-\sigma}} \frac{P_{i, t}}{P_{C^{i}, t}} \frac{P_{C^{i}, t-1}}{P_{i, t-1}} \Pi_{i, t}^{-1} \\
& \frac{C_{F, t}^{*-\sigma}}{C_{F, t-1}^{*-\sigma}} \frac{P_{F, t}}{\mathcal{E}_{i F, t} P_{F, t}^{*}} \frac{\mathcal{E}_{i F, t-1} P_{F, t-1}^{*}}{P_{F, t-1}} \Pi_{F, t}^{-1}=\frac{C_{t}^{i-\sigma}}{C_{t-1}^{i-\sigma}} \frac{P_{i, t}}{P_{C^{i}, t}} \frac{P_{C^{i}, t-1}}{P_{i, t-1}} \Pi_{i, t}^{-1} \\
& \frac{C_{H, t}^{*-\sigma}}{C_{H, t-1}^{*-\sigma}} \frac{P_{H, t}}{\mathcal{E}_{H F, t} P_{H, t}^{*}} \frac{\mathcal{E}_{H F, t-1} P_{H, t-1}^{*}}{P_{H, t-1}} \Pi_{H, t}^{-1}=\frac{C_{F, t}^{*-\sigma}}{C_{F, t-1}^{*-\sigma}} \frac{P_{F, t}}{P_{F, t}^{*}} \frac{P_{F, t-1}^{*}}{P_{F, t-1}} \Pi_{F, t}^{-1}
\end{aligned}
$$

for all $t$ with $\mathcal{C}_{H, t} \equiv 2 \int_{0}^{\frac{1}{2}} C_{t}^{j 1-\sigma \eta} d j$ and $\mathcal{C}_{F, t} \equiv 2 \int_{\frac{1}{2}}^{1} C_{t}^{j 1-\sigma \eta} d j$ and where $C_{F, t}^{*}, C_{H, t}^{*}$ are properly defined in Appendix A.3 and $P_{F, t}^{*}$ and $\mathcal{E}_{H F, t}^{2} P_{H, t}^{*} / P_{H, t}$ and $\mathcal{E}_{i H, t} P_{H, t}^{*} / P_{H, t}$ are defined according to (43) and using (44). Similar definitions apply to their foreign counterparts, while $P_{i, t} / P_{C^{i}, t}$ is determined consistently with 488.

Conditions (49) and (50) represent the aggregate good market clearing conditions and correspond up to a first order approximation to equation (3) and its foreign equivalent. Conditions (51), (52) and (53) are direct consequence of the profit maximization under Calvo pricing and can be approximated as in Phillips curve (1). Condition (55) corresponds to a first order expansion of the Euler equation (6). Notice that under regime $A, r_{t}^{i}=r_{F, t}$ for all $i \in\left[\frac{1}{2}, 1\right]$, under regime $B, r_{t}^{i}=r_{H, t}$ for all $i \in\left[0, \frac{1}{2}\right)$ and $r_{t}^{i}=r_{F, t}$ for all $i \in\left[\frac{1}{2}, 1\right]$, while under regime $C r_{t}^{i}=r_{H, t}=r_{F, t}$ for all $i$. The last conditions (56), (57) and (58) embed the risk sharing conditions in (41) and can be approximated up to the first order as in (7) and (8). In order to close the model we need to determine the optimal policy rules under the different regimes.

\section{B The Pareto-efficient allocation}

In this appendix we solve the social planner problem and find the conditions that characterize the Pareto-efficient allocation. The social planner maximizes the world welfare with respect to $Y_{t}^{i}, N_{t}^{i}$ and $C_{j, t}^{i}$ for all $i$ and $j$ : 


$$
E_{0} \sum_{t=0}^{\infty} \beta^{t}\left\{\int_{0}^{1} \frac{C_{t}^{i 1-\sigma}}{1-\sigma}-\frac{1}{\varphi+1} N_{t}^{i \varphi+1} d i\right\}
$$

where $C_{t}^{i}$ is defined as in 32 .

The constraints to the planner's problem are:

$$
\begin{aligned}
Y_{t}^{i} & =C_{i, t}^{i}+\int_{0}^{\frac{1}{2}} C_{i, t}^{j} d j+\int_{\frac{1}{2}}^{1} C_{i, t}^{j} d j \quad i \in[0,1] \\
Y_{t}^{i} & =A_{t}^{i} N_{t}^{i} \quad i \in[0,1]
\end{aligned}
$$

As in Galí and Monacelli (2009) we assume that the planner incorporates ex ante the optimal condition whereby consumption and production of each variety are identical within each region $i$. According to the first-order conditions:

$$
\begin{aligned}
& C_{t}^{i^{-\sigma}}=\left[\alpha_{s}\left(\frac{Y_{t}^{i \varphi+1}}{A_{t}^{i \varphi}}\right)^{1-\eta}+2\left(\alpha_{b}-\alpha_{s}\right) \int_{0}^{\frac{1}{2}}\left(\frac{Y_{t}^{j^{\varphi+1}}}{A_{t}^{j^{\varphi}}}\right)^{1-\eta} d j+2\left(1-\alpha_{b}\right) \int_{\frac{1}{2}}^{1}\left(\frac{Y_{t}^{j^{\varphi+1}}}{A_{t}^{j^{\varphi}}}\right)^{1-\eta} d j\right]^{\frac{1}{1-\eta}} \\
& \frac{Y_{t}^{i^{1+\varphi \eta}}}{A_{t}^{i^{(\varphi+1) \eta}}}=\left[\alpha_{s} C_{t}^{i^{1-\sigma \eta}}+2\left(\alpha_{b}-\alpha_{s}\right) \int_{0}^{\frac{1}{2}} C_{t}^{j^{1-\sigma \eta}} d j+2\left(1-\alpha_{b}\right) \int_{\frac{1}{2}}^{1} C_{t}^{j^{1-\sigma \eta}} d j\right]
\end{aligned}
$$

for all $i \in\left[0, \frac{1}{2}\right)$. Symmetric conditions apply to each region $i$ with $i \in\left[\frac{1}{2}, 1\right]$. The first condition in (61) states that at the margin the utility embedded into an additional unit of the composite consumption bundle $C_{t}^{i}$ should be equal to a CES aggregation of the additional disutilities entailed by its production. Conversely, the second condition in (61) rewrites the resource constraint in terms of aggregate consumption of each region $j$ by using the technological constraints and the other optimality conditions.

By taking the log-linear approximation to (61) and integrating them over $i \in\left[0, \frac{1}{2}\right)$ we find that:

$$
\begin{aligned}
& -\sigma \hat{c}_{H, t}^{e}=\alpha_{b}\left(\varphi \hat{y}_{H, t}^{e}-(\varphi+1) \hat{a}_{H, t}\right)+\left(1-\alpha_{b}\right)\left(\varphi \hat{y}_{F, t}^{e}-(\varphi+1) \hat{a}_{F, t}\right) \\
& (1+\varphi \eta) \hat{y}_{H, t}^{e}-(1+\varphi) \eta \hat{a}_{H, t}=(1-\eta \sigma)\left(\alpha_{b} \hat{c}_{H, t}^{e}+\left(1-\alpha_{b}\right) \hat{c}_{F, t}^{e}\right)
\end{aligned}
$$

where the suffix $e$ stands for efficient. By combining the two conditions in $(62)$ with their symmetric counterparts for the foreign area, we obtain:

$$
\hat{y}_{H, t}^{e}=\frac{\varphi+1}{\sigma+\varphi} \hat{a}_{H, t}+\frac{\left(\delta_{b}-\gamma_{b}\right) \sigma(\varphi+1)}{(\sigma+\varphi)\left(\left(2 \gamma_{b}-1\right) \sigma+\left(2 \delta_{b}-1\right) \varphi\right)}\left(\hat{a}_{H, t}-\hat{a}_{F, t}\right)
$$

where the suffix $e$ stands for efficient. Condition (63) expresses the log deviations of the efficient level of output in area $H$ in terms of area $H$ productivity and the productivity differentials between area $H$ and $F$. 